\title{
Toward Regeneration of the Heart: Bioengineering Strategies for Immunomodulation
}

\author{
Arianna Ferrini ${ }^{1,2}$, Molly M. Stevens ${ }^{1,3,4}$, Susanne Sattler ${ }^{2}$ and Nadia Rosenthal ${ }^{2,5 *}$ \\ ${ }^{1}$ Department of Materials, Imperial College London, London, United Kingdom, ${ }^{2}$ National Heart and Lung Institute and BHF \\ Centre for Research Excellence, Imperial College London, London, United Kingdom, ${ }^{3}$ Department of Bioengineering, \\ Imperial College London, London, United Kingdom, ${ }^{4}$ Institute of Biomedical Engineering, Imperial College London, London, \\ United Kingdom, ${ }^{5}$ The Jackson Laboratory, Bar Harbor, ME, United States
}

OPEN ACCESS

Edited by:

Ziad Mallat,

University of Cambridge,

United Kingdom

Reviewed by:

Nikolaos G. Frangogiannis, Albert Einstein College of Medicine, United States

Smadar Cohen,

Ben-Gurion University of the Negev,

Israel

*Correspondence:

Nadia Rosenthal nadia.rosentha/@jax.org

Specialty section:

This article was submitted to

Cardiovascular Biologics and

Regenerative Medicine,

a section of the journal

Frontiers in Cardiovascular Medicine

Received: 21 December 2018

Accepted: 26 February 2019

Published: 21 March 2019

Citation:

Ferrini A, Stevens MM, Sattler S and Rosenthal N (2019) Toward Regeneration of the Heart: Bioengineering Strategies for Immunomodulation. Front. Cardiovasc. Med. 6:26. doi: 10.3389/fcvm.2019.00026
Myocardial Infarction (MI) is the most common cardiovascular disease. An average-sized $\mathrm{Ml}$ causes the loss of up to 1 billion cardiomyocytes and the adult heart lacks the capacity to replace them. Although post-Ml treatment has dramatically improved survival rates over the last few decades, more than $20 \%$ of patients affected by MI will subsequently develop heart failure (HF), an incurable condition where the contracting myocardium is transformed into an akinetic, fibrotic scar, unable to meet the body's need for blood supply. Excessive inflammation and persistent immune auto-reactivity have been suggested to contribute to post-MI tissue damage and exacerbate HF development. Two newly emerging fields of biomedical research, immunomodulatory therapies and cardiac bioengineering, provide potential options to target the causative mechanisms underlying HF development. Combining these two fields to develop biomaterials for delivery of immunomodulatory bioactive molecules holds great promise for HF therapy. Specifically, minimally invasive delivery of injectable hydrogels, loaded with bioactive factors with angiogenic, proliferative, anti-apoptotic and immunomodulatory functions, is a promising route for influencing the cascade of immune events post-MI, preventing adverse left ventricular remodeling, and offering protection from early inflammation to fibrosis. Here we provide an updated overview on the main injectable hydrogel systems and bioactive factors that have been tested in animal models with promising results and discuss the challenges to be addressed for accelerating the development of these novel therapeutic strategies.

Keywords: myocardial infarction, injectable hydrogel, cardiac regeneration, immunomodulation, growth factors

\section{IMMUNE FEATURES OF CARDIOVASCULAR DISEASE AND HEART FAILURE}

Cardiovascular diseases (CVDs) is the leading cause of death worldwide (1). In Europe only, CVDs claim more than 4 million lives each year, accounting for $49 \%$ of death among women and $40 \%$ among men (2). Myocardial infarction (MI) is the most common CVD (1). MI occurs when the supply of freshly oxygenated blood to the left ventricle is blocked as a result of a prolonged coronary artery occlusion. This occlusion and the resulting ischemic damage cause the loss of up to 1 billion cardiomyocytes (CMs) (3). Given the limited intrinsic regenerative capacity of the heart, surviving cardiomyocytes increase in size more than in number (4) and a non-contractile fibrous scar is formed to avoid fatal cardiac rupture. 
Although cardiomyocyte death initiates an inflammatory response that is essential for early removal of necrotic debris and scar formation, persistent inflammation can cause immune-mediated tissue damage (5). Anti-cardiac autoreactivity of the adaptive immune system progressively contributes to structural remodeling and functional decline (6-8), inducing morphological changes such as left ventricular (LV) remodeling that compromises the function and pumping capacity of the heart. These cumulative immune responses lead to the progressive spiral toward heart failure (HF) (9), where the heart is incapable of generating sufficient cardiac output to meet the demands of the body.

HF has a poor prognosis and no effective treatment is available to date (10), the disease is associated with poor quality of life, high healthcare costs, and a high mortality rate $(11,12)$. Current treatments comprise pharmacotherapy, medical devices such as ventricular assist devices, and heart transplant. The first two strategies optimize the function of the remaining viable cardiomyocytes, and although successful in saving and improving quality of life they do not address the underlying causes of cell loss and restore lost cardiac tissue, and therefore cannot effectively manage the progression to HF. Heart transplantation remains the only effective treatment to restore fully functioning cardiac tissue $(13,14)$, but the limited amount of available donors and complications from immune rejection make it impractical for the number of people affected by HF (15). As a result, there is a pressing need for effective methods to regenerate damaged myocardium and prevent adverse remodeling.

Here we discuss the status quo of tissue engineering approaches to improve cardiac regeneration after MI, and how intended or fortuitous immunological properties of biomaterials may underlie their beneficial effects. We first focus on injectable in situ gelling systems and the relative material design criteria that need to be considered for cardiac repair applications. We then present an overview of the main bioactive molecules with pro-angiogenic, anti-apoptotic and anti-inflammatory properties, delivered in vivo as single or combined factors in animal models of MI. Finally, we discuss some of the challenges when considering a clinical translation of these strategies.

\section{HYDROGELS AS A NOVEL THERAPEUTIC APPROACH AFTER MI}

Tissue engineering and regenerative medicine have recently emerged as a prospective option for MI and HF treatment. The availability of engineered or regenerated cardiac tissue to supplant donated hearts would be a significant step forward in improving patient prognosis and advance treatments for MI. Biomaterial-based strategies are being developed to tackle cardiac regeneration post-MI, strengthened by the conclusion that $95-99 \%$ of therapeutic stem cells delivered to the infarcted heart are lost within the first $24 \mathrm{~h}$ (16-18). In addition to providing mechanical support for the damaged myocardial wall, tissue engineering strategies have the potential to enhance cell survival and cell retention, reducing immediate cell loss due to mechanical washout and promoting integration into the host tissue. Biomaterials not only to address the issue of cell engraftment but also aid in the clinical translation of therapies based on bioactive molecules, systemic administration of which is hindered by their short in vivo half-life, the need for repeated injections and high cost of treatment. By stably delivering bioactive molecules to the area of damage, biomaterials have the potential to counteract the morphological changes leading to HF by promoting angiogenesis and cell survival.

The two main strategies currently implemented for cardiac tissue engineering are cardiac patches or scaffolds and in situ gelling systems. Engineered scaffolds or patches are solid porous polymeric matrices which may have cells and/or bioactive molecules attached to them (19). These approaches are limited by the invasive procedure by which they are applied, as they require invasive surgeries for implantation and is not an option for patients with advanced HF, due to comorbidities that exclude them from undergoing surgery. In the 1990s, a therapeutic strategy involved ventricular restraints such as polymeric meshes enfolding the heart or sutured to its surface. Several studies have shown that they are effective in reducing infarct expansion by mechanically stabilizing the heart, limiting long-term changes in the LV geometry in large animal models (20-22) with minimal options for clinical translation (23), leaving cardiac patches and in situ gelling systems as the two main approaches currently investigated for cardiac tissue engineering (24).

In the gel category, hydrogels have received considerable attention as "water-swollen polymer networks" (23) that have a high percentage of water content similar to human tissue (25). They can be prepared from polymers of either natural or synthetic origin and they are able to absorb a considerable amount of water or biofluids, resulting in swelling with maintenance of their shape (26). As injectable fluid, they represent a minimally invasive approach (27) used for the localized delivery of bioactive molecules to target sites, allowing for well-controlled release kinetics and increasing the functional half-life of cargo molecules. As a delivery vehicle, hydrogels can also be used for "combination strategies," simultaneously encapsulating cells and bioactive molecules.

\section{DESIGN OF INJECTABLE BIOMATERIALS FOR CARDIAC TISSUE ENGINEERING}

When designing any biomaterial for tissue engineering application, important considerations include the function and composition of the target tissue. Biomaterials should have biological and physical properties mimicking those of the target tissue and should be able to degrade upon tissue regeneration. Materials for myocardial tissue engineering should ideally be designed to offer mechanical support to the infarcted myocardium, while not interfering with 
synchronization and myocardial geometry. In this respect, an injectable/in situ polymerizable material is advantageous over a patch because upon injection it can uniformly disperse in the myocardial wall remaining anchored by interstitial placement (28).

\section{Injectability and Delivery Methods}

A hydrogel that can pass through a fine gauge needle $(27 \mathrm{G})$ can be safely administered through intramyocardial injection with a minimally invasive approach (29). Injectability is achieved when the gelation of the hydrogel is either initiated but not completed in the needle or initiated and completed after delivery at the target site. Importantly, polymerization time should be in the order of tens of minutes or shorter so that to ensure the hydrogel is successfully localized and not washed out with the contraction of the heart (30). In the context of cardiac repair, injectable hydrogels represent a minimally invasive approach, decreasing the damage incurred to the targeted and surrounding tissue during delivery (27). The ideal method of delivery providing a quick path to clinical translation would use current catheter technology, but although highly patient-compliant, it poses some challenges for the designing the material which must be maintained in liquid form for the duration of the injection procedure (up to $1 \mathrm{~h}$ ) and then solidify into a hydrogel once within the myocardial wall. A thermo-responsive hydrogel delivered through a cooled injection system could overcome this challenge.

There are three main methods for the clinical delivery of injectable hydrogel therapies, each with its advantages and limitations. The first is intracoronary injection with a catheter via an inflated percutaneous transluminal coronary angioplasty (PTCA) balloon. This approach is unique as it exploits leaky vessels in the damaged region for the delivery, instead of a puncture injection, and it utilizes currently available technology without the need for additional training. However, it requires special material design and the volume of delivered material cannot be controlled well due to passive leakage from the target vessel (27). A second approach is direct epicardial injection into the heart; advantages of this method include an accurate location control while a drawback is that endoscopic application or open chest access required for the administration are invasive procedures. Lastly, another less invasive approach is transendocardial injection via catheter combined with imagining technology such as NOGA $^{\circledR}(31)$. However, this method requires specialized training for both the injection catheter and the imaging modality so is not currently routinely performed (27).

\section{Stiffness and Mechanical Support}

Considerations regarding the mechanical requirements of a biomaterial must take into account the in vivo model where it will be tested, since the forces exerted by a human heart will vastly differ from those of a small rodent. Physiologically, the stiffness of the human myocardium ranges from $20 \mathrm{kPa}$ at enddiastole to $500 \mathrm{kPa}$ at the end-systole $(32,33)$, whereas that of the rat myocardium goes from 0.1 to $140 \mathrm{kPa}(33)$. As the collagenous scar forms, the infarcted myocardium undergoes a time-dependent stiffness change becoming less and less flexible.
As measured by atomic force microscopy (AFM), the baseline elastic modulus, which measures the ability of a material to resist deformation, of non-infarcted rat myocardium is $18 \pm 2 \mathrm{kPa}$ (34). In the first $24 \mathrm{~h}$ after MI the stiffness of infarcted myocardium is relatively soft $(4-17 \mathrm{kPa})(35)$, whereas in the 2 weeks post$\mathrm{MI}$, significant fibrosis is formed resulting in a threefold increase in the elastic modulus $(55 \pm 15 \mathrm{kPa})$ (34). It is known that the physical characteristics of the microenvironment have an effect on the survival and differentiation of the engrafted cells (35). Therefore, the response to cell and material implantation will vary with the stiffness of the infarcted tissue, which in turn depends on the time post-infarction (30). A material envisioned to provide long-term mechanical support should have a high-end stiffness, matching the one of the native myocardium, whereas a material designed for the injection and the delivery of cells and/or bioactive factors should have a low stiffness, as long as it is able to withstand the contraction/dilation of the heart.

\section{Application Time Post-MI}

Since recent and old infarcts have their distinct features and challenges, an important consideration for material design is the time post-MI at which the material is injected. Depending on injury stage and extent of remodeling, the status of MI is categorized as acute (1-7 days), sub-acute (1-3 weeks) or chronic ( $>1$ month). Application of therapeutic agents in chronic models has so far shown little success in improving regeneration, and regenerative therapy in chronic MI remains a challenge. While acute MI involves early ventricular damage, chronic MI changes the ventricular shape, causing a time-dependent dilation, and LV hypertrophy (36). Delivering therapeutic factors shortly after an MI might protect the remote myocardium, minimize scar formation and ultimately attenuate pathological remodeling. However, delivering cells or bioactive molecules too soon risks exposing them to a hostile ischemic and inflammatory environment. The time of injection in in vivo studies ranges from immediate (37-40) to 1 week $(41,42)$ to 2 months post-MI (37). The most common approach in animal models is an immediate injection, which unfortunately does not accurately mimic the clinical situation because patients would not receive a therapy for a minimum of several hours, if not days, post-MI. Hence, studies investigating the effect of biomaterial injections at later time points such as 2 months are valuable to test the possibility to avoid scar expansion and LV dilation in patients that did not receive an earlier treatment (27). Many studies have looked at the importance of application timing, showing how it underpins the benefit seen in the long term. For example, in a murine model of MI, intramyocardial injection of a collagen matrix is only effective at preventing negative ventricular remodeling and long-term decline of cardiac function if administered $3 \mathrm{~h}$ after MI rather than 1 week or 2 weeks after [38]. On the other hand, a study investigating the effect of an injectable alginate implant showed beneficial effects both in recent $(<7$ days) and old (60 days) infarctions, indicating how other concomitant factors (animal model used, one vs. multiple injections, sites of the injections) could contribute to the observed outcome (37).

Timing of therapy may be particularly crucial if an immunomodulatory component is included. The immune 
response after an MI follows a time-dependent course with distinct but overlapping phases and the outcome of a specific immunomodulatory treatment will be highly dependent on the prevailing inflammatory environment (43), as depicted in Figure 1. During the early inflammatory phase, proinflammatory monocytes and macrophages together with neutrophils infiltrate the injured area, clearing the necrotic cardiomyocytes (44). Here, the target for a biomaterial-based strategy would be to promote cardiomyocyte survival and attenuate leukocytes and acute inflammation by supporting efficient resolution of inflammation. The second, proliferative, phase is characterized by fibroblasts and endothelial cell proliferation, ECM deposition and formation a vascularized granulation tissue, accompanied by recruitment of lymphocytes, angiogenesis, and myofibroblasts differentiation (44). At this stage, a biomaterial therapy should aim at regulating macrophage phenotype and function, controlling fibroblast activity and matrix remodeling and promoting angiogenesis. During the final maturation phase, myofibroblast activation recedes and a mature collagen-rich scar is formed which is mostly devoid of cardiomyocytes, hence non-contractile (44). At this point, the goal for any strategy is the replacement of lost cardiomyocytes, potentially delivering cells through a biomaterial approach. In parallel, immunomodulatory strategies may need to forego local factor delivery and aim at targeting ongoing systemic immune activation (8).

\section{Responsiveness to External Stimuli}

An advantage of using injectable delivery systems is the opportunity to tailor polymerization and drug release characteristics to respond to clinically relevant stimuli present in the target tissue microenvironment. Stimulus-responsive "smart" polymers (45) have the unique property of undergoing gelation or cargo-release in response to environmental stimuli (46). Stimuli that have been exploited for regenerative medicine applications in vitro and in vivo, including cardiac repair, include temperature $(47,48), \mathrm{pH}(49,50)$, light $(28)$, and enzymes such as metalloproteinases (51).

Temperature-responsive and biodegradable hydrogels are usually in the form of an injectable solution at room temperature, becoming a biodegradable solid at $37^{\circ} \mathrm{C}$. These are advantageous for cardiac repair since they undergo a gelation process under physiological conditions that allow them to support cell viability and bioactivity of the encapsulated molecules while avoiding damage to the adjacent tissue (52). Another stimulus that can be used to trigger hydrogel polymerization is $\mathrm{pH}$, particularly relevant in the context of myocardial infarction where the $\mathrm{pH}$ drops from the physiological value of 7.4 to 6.5-6.8 due to the switch from aerobic to anaerobic metabolism (53). An acidic microenvironment such as the ischemic myocardium is also an endogenous danger signal alerting the innate immune system and contributing to inflammation (54). Specifically, the acidification of the environment cause macrophages to increase the secretion of the pro-inflammatory cytokines IL- $1 \beta$ and IL-18 (54). Since IL-1 antagonist therapies are being developed for the treatment of MI (55-57), the use of a $\mathrm{pH}$-sensitive drug delivery hydrogel system in a context where IL-1 levels are elevated would potentially be an effective and novel anti-inflammatory therapeutic strategy.

\section{Bioactivity of the Released Molecules}

Another important parameter to consider when designing injectable hydrogels is their ability to protect bioactivity of their biological cargo. In this respect, studies testing these systems in vivo should compare the bioactivity of the native factor with the released factor. In general, growth factors and

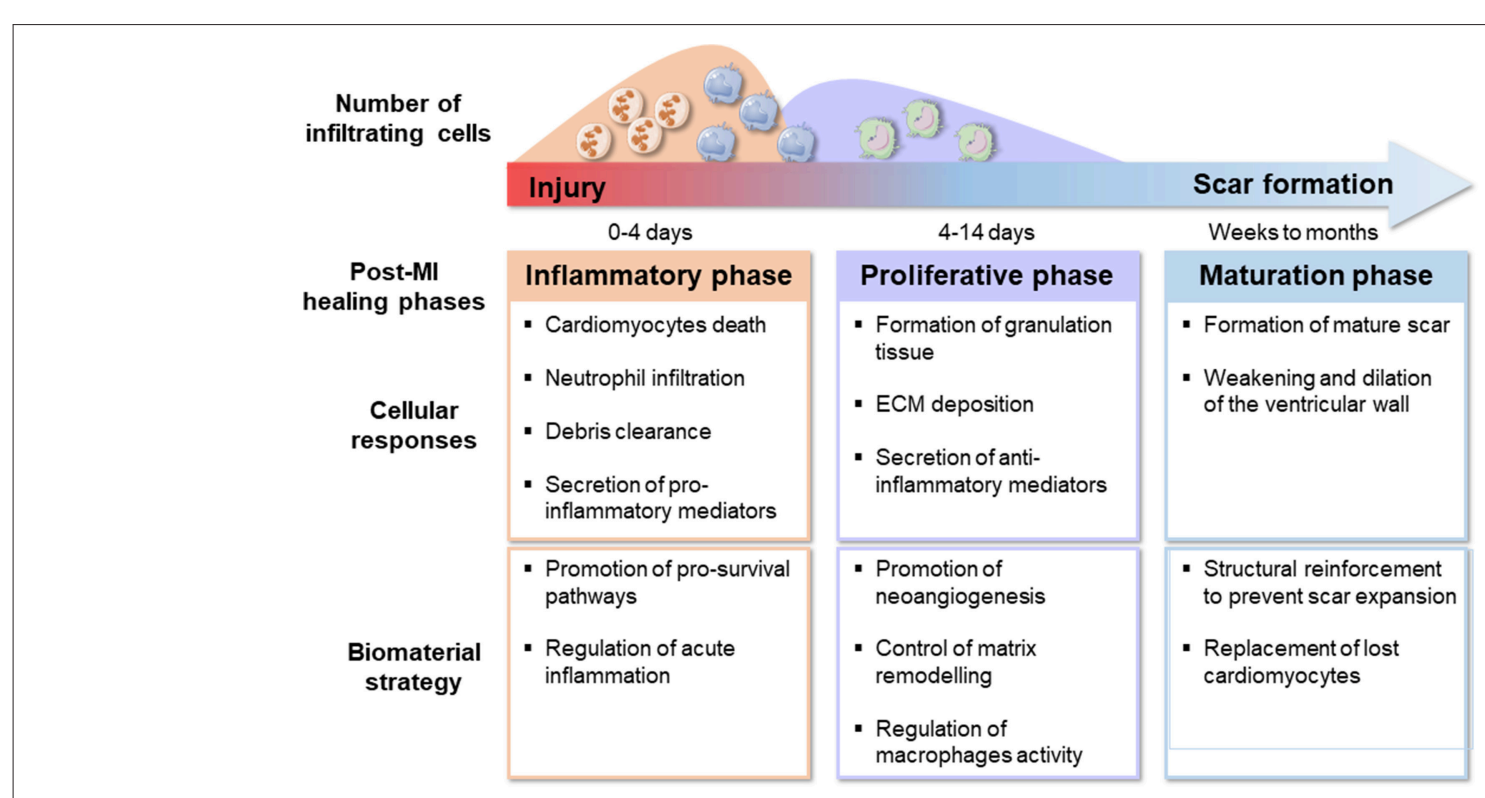

FIGURE 1 | Representation of biomaterial strategies to tackle different post-MI phases. 
cytokines are unstable molecules with short in vivo half-lives. In the inflammatory and acidic environment of the infarcted myocardium, the bioactivity and stability of these molecules is further decreased due to the abundance of proteases and high oxidative stress (58). Hence, hydrogels can act as reservoirs for the sustained and localized delivery of these important regulators under protease-rich conditions. Pioneering work by Langer and Folkman showed that molecules encapsulated in polymer matrixes can display a sustained released for up to 100 days (59). Usually, molecules released from hydrogels exhibit an initial "burst release," followed by a sustained release profile with slower release rate; however, release kinetics are unique to every biomaterial-cargo combination and must be determined in each case.

A novel class of injectable hydrogels that present a promising option in regard to maintain the bioactivity of the cargo are coacervate hydrogels (60). They are formed by polyelectrolytes of opposing charges mixed together to form droplets held by electrostatic forces (61). Once encapsulated within the coacervate phase, unstable proteins or drugs are separated and protected from the surrounding environment, thereby preserving their bioactivity (60). Moreover, due to their size, coacervates can be applied via very fine gauge needles, important for minimizing damage associated with injection (60).

\section{Biocompatibility and Immunomodulation}

Biocompatibility is defined as "the ability of a material to perform with an appropriate host response in a specific application" (62). The concept of biocompatibility is a characteristic of the material-host interaction more than a material property (63). Specifically, the material should not initiate a substantial foreign body response in vivo. This does not preclude the activation of an immune response but shifts the focus on controlling the type and the magnitude of the response in order to prevent further cardiac damage (29). In the past, emphasis was put on minimizing the inflammatory response to biomaterials altogether. However, recent studies demonstrate that the endogenous healing and regeneration processes can be supported by fine-tuning the balance between pro- and anti-inflammatory response (64). As a relevant example, macrophages are highly dynamic and responsive to their micro-environment, and biomaterials have the potential to alter the macrophage response and their polarization toward a regenerative rather than an inflammatory phenotype after MI. The effect of biomaterials on macrophage polarization has been investigated by several groups, focusing on the responses to cellular or acellular grafts (65), natural (66) or synthetic (67) origin and different fibers and porous sizes $(68,69)$. Badylak et al. compared a natural-derived scaffold made of porcine small intestinal submucosa (SIS) with its crosslinked version, known as CuffPatch (CDI-SIS) (66). The SIS patch induced a strong mononuclear response at 1-, 2-, and 4-weeks post implantation, as determined by $\mathrm{CD}_{163}{ }^{+}$macrophages. On the other hand, the crosslinked CDI-SIS patch elicited the recruitment of an equal proportion of $\mathrm{CD} 80^{+}$pro-inflammatory and $\mathrm{CD}_{163}{ }^{+}$anti-inflammatory macrophages at 1 - and 2weeks, with the anti-inflammatory population predominant in later time points and observed at the border zone rather than infiltrating the scar. Physical properties such as fiber diameter and pores size are also able to influence macrophages: larger fibers and pore size of different types of scaffolds induce the differentiation of anti-inflammatory macrophages, characterized by an increased production of wound-healing mediators such as Vascular Endothelial Growth Factor (VEGF) and basic Fibroblast Growth Factor (bFGF) and more potency in promoting capillary formation in vitro $(68,69)$. This illustrates how small changes in material properties can have significant effects on the immune response elicited by the material and how the impact of the biomaterial on the macrophage population may significantly contribute to the overall success of a biomaterial strategy.

\section{HYDROGEL-BASED APPLICATIONS IN CARDIAC TISSUE ENGINEERING}

Injectable hydrogels without addition of cells or molecular therapeutics have elicited functional improvements and prevention of left ventricular dilation in small and large animal models. However, the combination of injectable strategies with the delivery of growth factors, cytokines or other bioactive molecules shows great promise as a therapeutic approach, as hydrogels can help overcome the challenges associated with high diffusion rates and their half-life in vivo as discussed above (23).

\section{Injectable Hydrogels for Mechanical Support}

Injectable hydrogels can be used as a bulking agent after MI, providing mechanical support to the infarcted heart, and preventing ventricular remodeling by attentuating wall stress $(23,70)$. This has not only been shown in small and large animal models but also confirmed by computational models (71-73). One of the earliest materials used for cardiac repair was fibrin, a biodegradable protein involved in the coagulation cascade (74). The field of acellular injectable materials was pioneered by Christman et al. who explored the effects of fibrin glue as post-MI bulking agent $(75,76)$, showing its ability to recruit endothelial cells, and to increase capillary density, probably due to the fact that fibrin contains binding domains for angiogenic factors, such as FGF (77). An ECM-derived hydrogel, specifically from pig heart ventricles, has also been investigated as an acellular bulking agent, following percutaneous delivery via trans-endocardial injection in a rat model of MI (78). Results showed a decrease in the loss of endogenous cardiomyocytes and a preserved cardiac function and were later further confirmed in pig models (79), demonstrating that providing cardiac-specific cues to the injured myocardium via decellularized cardiac ECM hydrogels is a promising strategy to reduce infarct size and promote tissue formation (23).

Hydrogels made of alginate, a naturally occurring linear polysaccharide found in brown seaweed algae, are of high interest for tissue engineering applications, due to their biocompatibility, non-thrombogenic nature and resemblance to ECM $(80,81)$. Alginate hydrogel injection has shown beneficial results in rat and porcine models of MI $(37,82)$ although, unlike fibrin, alginate must be modified with adhesive peptides to 
facilitate cell binding (83). Leor et al. tested the effects of intracoronary injection of alginate hydrogel in a healthy swine heart, with no evidence of biomaterial deposition, necrosis and inflammation at the injection site (82). However, being a material of natural origin, there is a risk of contaminants, including mold, yeast and bacteria, with the latter contributing to the presence of endotoxins, mitogens and pyrogens (84). Since proinflammatory cytokines play a role in the pathophysiology of $\mathrm{HF}$ (85), these contaminants must be eliminated from biomedical alginates for cardiac applications. Hence, the production of alginate hydrogels for clinical use is strictly regulated by several agencies worldwide (84). Recently, injections of a commercially available calcium alginate hydrogel (Algisyl$\mathrm{LVR}^{\mathrm{TM}}$ ) were evaluated for their ability to reduce LV wall stress in HF patients with an ejection fraction (EF) $<40 \%$ (72). Three months after treatment, LV wall thickness increased by $20 \%$ and end-systolic volume (ESV) decreased by 30\%, showing for the first time that an acellular alginate hydrogel might be beneficial in the treatment of HF patients (72). Another study (AUGMENT-HF trial) investigated direct injections of alginate hydrogel in the myocardium of 113 patients; the material was administered through left thoracotomy with multiple intramyocardial injections and it was effective in improving cardiac function in chronic HF patients (86).

Synthetic hydrogels have also been tested as acellular in situ gelling systems. For example, a material consisting of $\alpha-$ cyclodextrin $(\alpha-C D)$ and poly (ethylene glycol) (MPEG-PCLMPEG) triblock copolymer that can form a gel in situ has shown functional LV improvement when injected in rodents models $(70,87)$. Fujimoto et al. designed and tested a biodegradable thermo-responsive hydrogel made of $\mathrm{N}$-isopropylacrylamide (NIPAAm), acrylic acid (AAc) and hydroxyethyl methacrylatepoly(trimethylene carbonate) (HEMAPTMC) which formed a gel at body temperature (48). Overall, this biodegradable material improved cardiac function and preserved the thickness of the ventricular wall compared with $\mathrm{PBS}$ injection in a rat model of MI. Specifically, the hydrogel distributed in the anterior wall and was infiltrated by macrophages and fibroblasts. This indicates that the macrophage phagocytic and secretory activity leads to a faster hydrolytic cleavage of the hydrogel in vivo rather than in vitro (48). Hydrogels are usually degraded by hydrolysis and the resulting small particles are phagocytized by macrophages at the injection site. Macrophage infiltration is associated with a higher expression of VEGF and bFGF around the newly formed vessels and these locally secreted angiogenic factors might positively influence tissue remodeling $(48,88)$.

\section{INJECTABLE HYDROGELS FOR THE DELIVERY OF BIOACTIVE FACTORS}

Due to their critical role in controlling cellular functions and orchestrating tissue regeneration, bioactive factors have received growing interest for regenerative applications in cardiovascular medicine. Many studies now highlight how the beneficial effects derived from the administration of stem cells into the infarcted myocardium are in fact due to the paracrine effects of secreted factors, rather than from direct action of the cells (89-93). This has been reviewed thoroughly elsewhere (94-96). Factors that activate specific intracellular pathways linked to cardioprotection include intermediates in the PI3K-Akt and MEK1/2-Erk1/2 prosurvival kinase pathways (97). However, as discussed above the therapeutic potential of these molecules is limited by their high rate of diffusion, short biological half-life (98), low plasma stability and low specificity to target organs (99). For example, post-MI intraperitoneal administration of a cocktail of growth factors in rats did not improve cardiac function, infarct size or neovascularization (98) and a single intracoronary infusion of FGF in patients did not significantly improve myocardial function in a phase 1 clinical trial (100). Therefore, the successful clinical translation of tissue reparative benefits of bioactive factor depends on new formulation and/or delivery approaches (99).

In addition to providing mechanical support, hydrogels can also serve as a water-rich matrix to encapsulate regenerative factors, representing a promising option for post-MI treatment. Bioactive factors loaded into hydrogels to test their ability to locally modulate cardiac repair include angiogenic (VEGF, FGF), anti-apoptotic (IGF-1, NRG- $\beta$ ), proliferative (SDF-1) and immunomodulatory (IL-10, TIMP-3) molecules (Figure 2).

\section{ANGIOGENIC FACTORS}

Angiogenesis refers to the development of blood vessels from a pre-existing vascular bed. Clinically, the objectives can be to either block vessel formation to treat tumors or to stimulate angiogenesis in states of insufficient blood flow such as the ischemic heart disease (101). In the context of myocardial infarction, angiogenic therapy may salvage the ischemic tissue, especially in the early stages post-MI. Angiogenesis occurs in the granulation tissue during the proliferative phase postMI. However, supporting neovascularization of the viable, surrounding myocardium at the infarct border zone may improve the process of tissue remodeling (102). Most studies have focused on the regenerative potential of VEGF and FGF. Localized and low-dose delivery of pro-angiogenic factors is particularly important because, regardless of how efficient the uptake, a considerable proportion of an angiogenic factor injected into a vessel supplying the target tissue will spill into the systemic circulation and expose non-target tissue to its biologic effects $(103,104)$. This is highly relevant for VEGF and its angiogenic effects because high doses of VEGF may result in the unregulated formation of haemangiomas (105) or vascular leakage that leads to oedema and nitric oxidedependent hypotension $(106,107)$. Thrombocytopenia and renal toxicity are the most likely side effects of high doses of FGF (108). Additionally, the immune system is not normally exposed to high doses of these factors and can potentially develop antibodies against them, leading to decreased administration efficacy. Hence, the use of injectable hydrogels that allow a sustained yet localized delivery of pro-angiogenic factors is a promising option for post-MI treatment. Examples of injectable biomaterials tested for the delivery of pro-angiogenic factors in animal models are summarized in Table $\mathbf{1 .}$ 


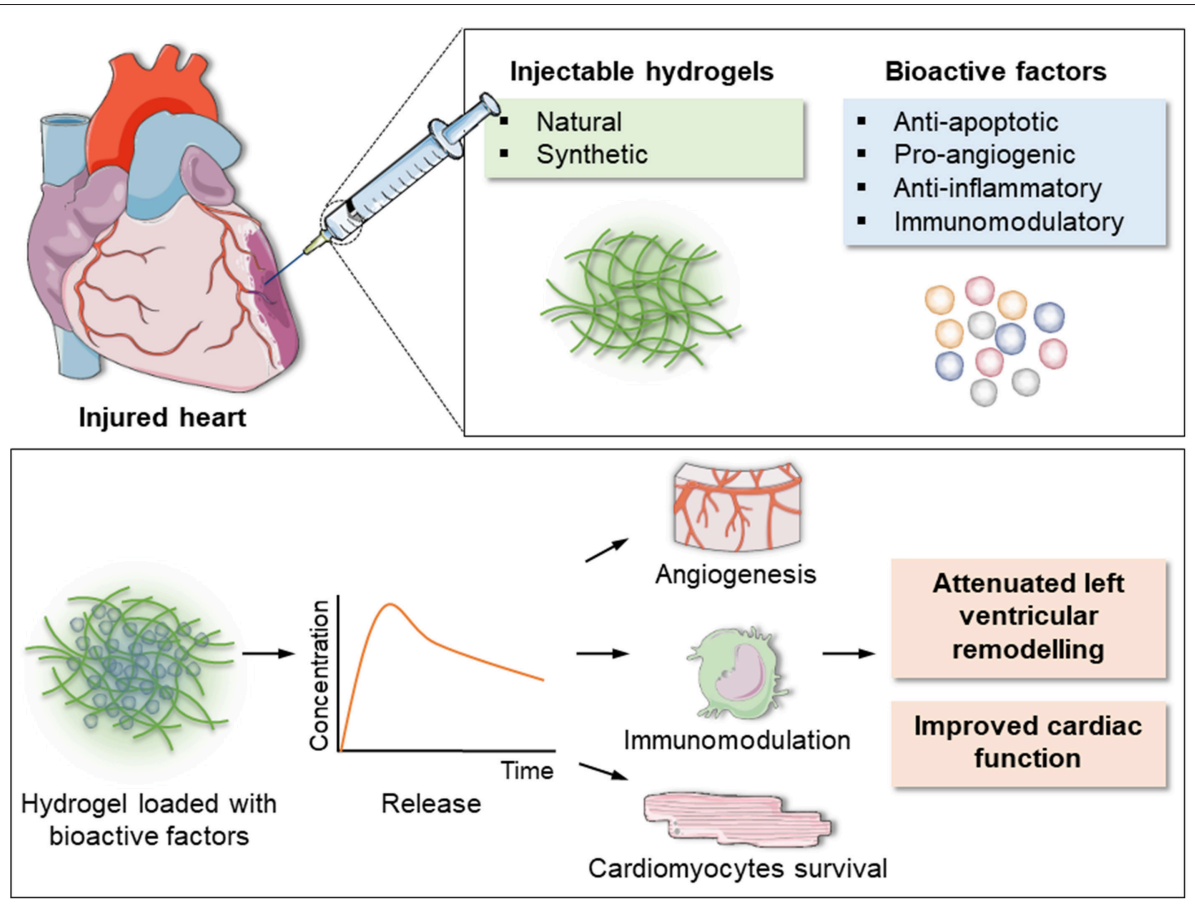

FIGURE 2 | Schematic of the injectable hydrogel approach for cardiac repair. Injectable hydrogels of either natural or synthetic origin can be loaded with bioactive factors with anti-apoptotic, pro-angiogenic, anti-inflammatory, and immunomodulatory actions. The encapsulated factors are released over time, inducing formation of new blood vessels, modulation of inflammation and post-MI immune response and cardiomyocytes survival. This eventually results in reduction of left ventricular remodeling and improved overall cardiac function.

\section{Vascular Endothelial Growth Factor (VEGF)}

VEGFs are a family of glycoproteins of which VEGF-A (also called VEGF-1) is the most extensively studied. Other members of the family, which shares structural homology, are VEGF-C, VEGF-B, VEGF-D and VEGF-E (117). Four species of VEGF$A$ have been identified, differing in the number of amino acids $\left(\mathrm{VEGF}_{121}, \mathrm{VEGF}_{165}, \mathrm{VEGF}_{189}\right.$, and $\left.\mathrm{VEGF}_{206}\right)$. VEGF 165 is the most abundant and predominant isoform of VEGF in the heart. Since it is the major regulator of angiogenesis in the heart, $\mathrm{VEGF}_{165}$ is also the most commonly used for therapeutic angiogenesis post MI (117). The first study showing its cardioprotective effects dates back to 1997 (118). Since then, many approaches have been tested for VEGF delivery to the ischemic heart, including gene therapy $(119-121)$ and intravenous and intracoronary administration $(122,123)$. The clinical trial VIVA assessed the effects of intracoronary infusion of recombinant human vascular endothelial growth factor (rhVEGF) in patients with chronic myocardial ischemia, showing a well-tolerated safety profile but no clinical improvements over placebo by day 60 (124). However, by day 120, rhVEGF at high dose led to significant improvement in angina and increasing trends in the Exercise Treadmill Test (ETT). As in several other trials $(122,125,126)$, VIVA showed a dose-dependent effect, highlighting once more the need for controlled and sustained release.

Various types of hydrogels, either of natural or synthetic origin, have been used for the delivery of VEGF. PEG-based hydrogels provide several advantages for in vivo applications and they have been extensively used in regenerative medicine due to their high water content and the fact that they can provide a three-dimensional environment similar to soft tissue, allowing distribution of oxygen, nutrients and metabolites (127-129). Recently, a biosynthetic injectable hydrogel consisting of polyethene glycol and fibrinogen (PEG-fibrinogen) loaded with VEGF and administered by intramyocardial injection showed myocardial function protection and improved vascularization in a rat $\mathrm{MI}$ model (109).

The most common approach for the encapsulation of a bioactive factors into an injectable hydrogel is simply by mixing it with the polymer solution. However, previous studies have shown that if angiogenic factors are immobilized on a scaffold, their angiogenic potential is enhanced $(130,131)$. Along these lines, a slightly different approach undertaken by $\mathrm{Wu}$ et al. was to conjugate VEGF to a [Poly ( $\delta$-valerolactone)block-poly (ethylene glycol)-block-poly ( $\delta$-valerolactone) (PVL-b-PEG- $b$-PVL)] instead of mixing it with the solution (52). All the conditions (hydrogel alone, hydrogel mixed with VEGF and hydrogel conjugated with VEGF) were able to significantly attenuate adverse cardiac remodeling. However, VEGF-conjugated hydrogels were better in boosting angiogenesis, likely because the conjugation was able to extend the biological activity of VEGF over the 42 days of biomaterial degradation (52). 
TABLE 1 | Exemplar injectable biomaterials used for the in vivo delivery of pro-angiogenic growth factors in animal models of MI.

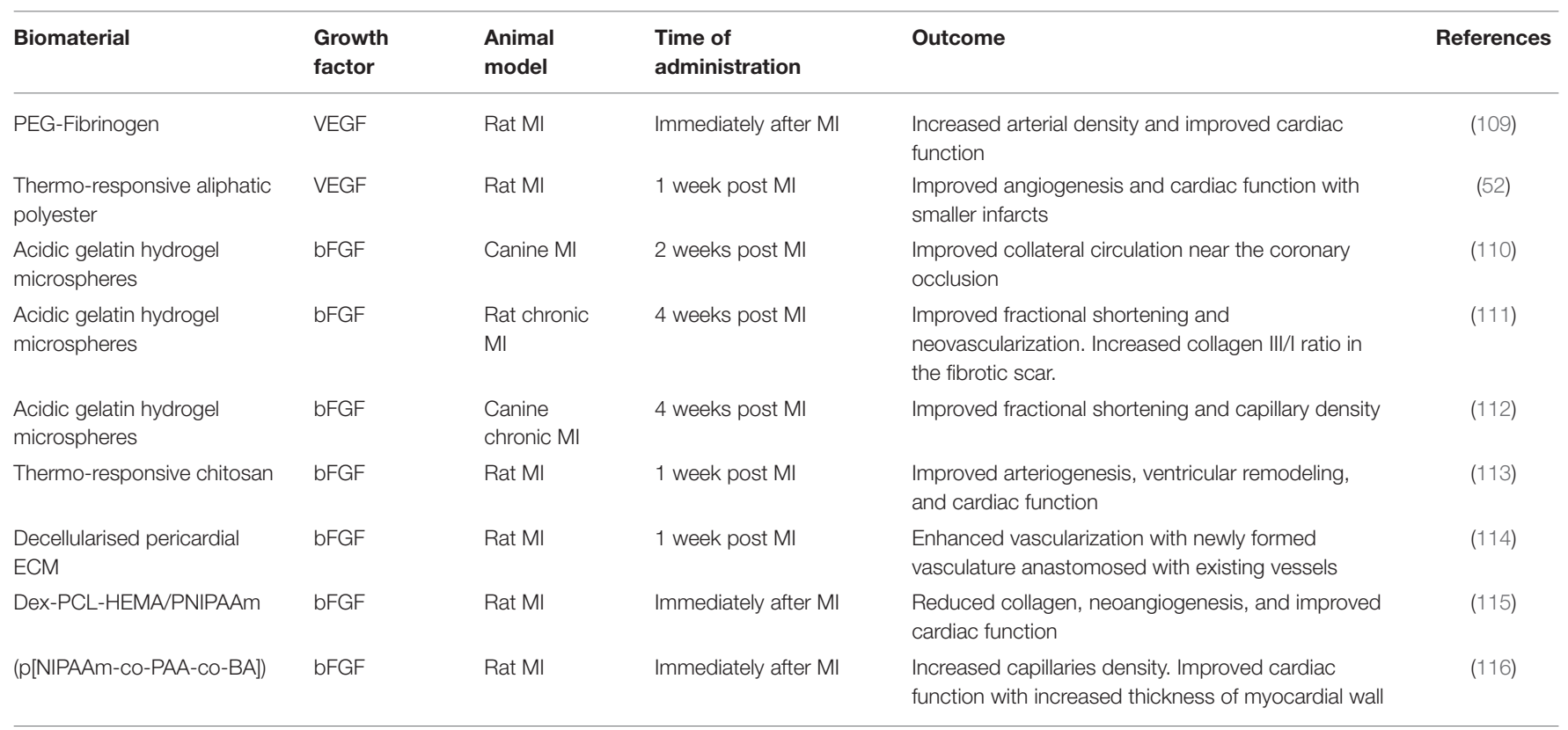

These studies were mainly focused on material design and characterization, and cardiac function was assessed by echocardiography. Immunomodulatory effects of VEGF were not tested. Importantly though, VEGF family factors not only have a direct effect on endothelial cell survival and proliferation, thus control new vessel formation and permeability, but also recruit inflammatory and regenerative cells such as myeloid and progenitor cells (102).

\section{Basic Fibroblast Growth Factor (bFGF)}

bFGF, a $16 \mathrm{kDa}$ monomeric factor, is the most potent angiogenic factor in the FGF family and it affects migration and proliferation of endothelial cells, smooth muscle cells and fibroblasts (115). However, its short half-life of only 3 min and side effects induced by high dose administration have hindered a robust clinical translation so far. Since it was first demonstrated that FGF could increase the number of capillaries and arterioles in the infarcted dog heart (132), it has been widely used in animal models (47, $104)$ and clinical trials $(100,133,134)$, showing treatment safety but not yet demonstrating efficacy.

The first biomaterials used for local delivery were bFGFimpregnated acidic gelatin hydrogel microspheres (AGHM), improving collateral circulation to the infarcted area after coronary occlusion in dogs significantly more than the free-form bFGF (110). Gelatin microspheres were also used to deliver bFGF in several hindlimb ischemia large animal models $(135,136)$. These studies showed promising results, leading to progression to clinical trials in patients with critical limb ischemia $(137,138)$. Currently, the same approach is being tested in small (111) and large animal models (112) of chronic MI. The improved cardiac contractile function seen in these recent studies shows how treatment with the sustained release of bFGF from gelatin hydrogels could be clinically translated not only for peripheral cardiovascular diseases but also for chronic MI.
In addition to gelatin microspheres, temperature-responsive chitosan was used for the delivery of FGF post-MI by Wang et al. (113). In this study, FGF was encapsulated in a thermoresponsive chitosan hydrogel upon intra-myocardial injection. This system significantly improved cardiac function compared to injecting FGF alone in a rat model of chronic MI (hydrogel injection 1-week post-MI) (113). bFGF also retains its bioactivity when delivered through natural-derived hydrogels such as decellularized pericardial ECM (114) or synthetic materials such as ( $p$ [NIPAAm-co-PAA-co-BA]) (50). Recently, bFGF (139) has shown overall amelioration of ischemic injury caused by $\mathrm{MI}$ in a mouse model using coacervate hydrogels (60).

As an example of the immunomodulatory responses to hydrogels, Garbern et al. designed a dual responsive polymer made of poly( $N$-isopropylacrylamide-co-propyl acrylic acid-cobutyl acrylate) ( $p$ [NIPAAm-co-PAA-co-BA]) which is a liquid at $\mathrm{pH} 7.4$ and $37^{\circ} \mathrm{C}$ and forms a gel at $\mathrm{pH} 6.8$ and $37^{\circ} \mathrm{C}$. They hypothesized that the ability of this polymer to form a reversible gel under the acidic conditions of the ischemic myocardium $(\mathrm{pH}$ 6.8) would allow it to first act as a depot system for the release of bFGF, and secondly to promote polymer dissolution once the tissue has returned to physiological $\mathrm{pH}$ (116). The system was tested for its efficacy in vivo in a rat model of MI, showing that it was able to provide a spatiotemporally controlled release of bFGF which in turn promoted angiogenesis, and improved cardiac function (116). Interestingly, the inflammatory response quantified by CD45 staining at day 28 was higher in animals injected with the polymer compared to saline. Near the polymer injection site, there was a significant macrophage infiltration and foreign body giant cells were also found, evidencing a chronic inflammation response. Macrophages promote angiogenesis and produce proangiogenic factors such as VEGF, IGF-1, and bFGF (140). Hence, it is possible that the enhanced presence of macrophages in polymer-treated animals has a beneficial effect 
by further improving the angiogenic response. However, time points past 28 days are needed to elucidate if the inflammatory response will be resolved appropriately to avoid detrimental effects long-term.

\section{ANTI-APOPTOTIC FACTORS}

Cardiomyocytes apoptosis is responsible for most of the myocyte death from the early stages of MI to the progression to HF. It is in fact not only detected in the infarct area, but it extends to the viable myocardium in remote non-infarcted regions, characterizing all post-MI phases $(61,141,142)$. Antiapoptotic therapeutic interventions therefore seem a potential therapeutic strategy and could involve the use of injectable hydrogels to deliver anti-apoptotic molecules to attenuate the loss of viable myocardium. Insulin-like Growth Factor 1 (IGF-1) and Hepatocyte Growth Factor (HGF) can both activate the PI3K/Akt pathway, enhancing cell survival, and reducing cardiomyocyte apoptosis resulting in improved cardiac function $(61,143)$. Examples of chemokines able to prevent myocyte apoptosis with demonstrated effectiveness are Granulocyte colony-stimulating factor (G-SCF) (144) and erythropoietin (EPO) $(145,146)$.

\section{Insulin-like Growth Factor-1 (IGF-1)}

IGF-1 is a $72 \mathrm{kDa}$ polypeptide which plays key roles in cell survival, proliferation, and differentiation via different signaling pathways such as Ras-Raf mitogen active protein kinases and phosphoinositide 3-kinase/Akt pathway (147). Buerke et al. carried out the first study to show acute cardioprotective effects of IGF-1, demonstrating that it reduced myocardial necrosis, apoptosis, and neutrophil accumulation (148). Since then, the beneficial effects of IGF-1 post-MI have been investigated by several groups employing several strategies including IGF-1 myocardial overexpression $(149,150)$, gene therapy $(151)$, and systemic (152) and local administration (153). IGF-1 transgenic overexpression not only activates survival signaling pathways in the cardiomyocytes, but also mediates myocardial repair by modulating the inflammatory response post-MI with decreased expression of the pro-inflammatory cytokines IL- $1 \beta$ and IL- 6 and increased expression of the anti-inflammatory IL-4 and IL10 compared to wild type mice (154). Moreover, cardiac-specific overexpression of IGF-1 resulted in early accumulation of innate immune cells at day 3 post-MI, with a reduction of inflammatory myeloid populations (149). Similar trends were found when IGF-1 was delivered through a single intravenous injection of AAV9 containing a cardiac-restricted IGF-1 isoform (151). These findings are supported by previous studies that identified antiinflammatory effects of IGF-1 in hyper-inflammatory conditions, which were due to the induction of regulatory $\mathrm{T}$ cells $(155,156)$.

Addition of IGF-1 to cell therapy strategies enhances the benefit of cell transplantation by promoting cell survival (157). Recently, IGF-1 was delivered together with Bone Marrow Stem Cells (BMSC) in a rabbit model of MI through biotinylated self-assembly peptides and was able to suppress cardiomyocyte apoptosis and promote the expression of cardiomyocyte-specific proteins (158). These findings were confirmed for different regenerative medicine applications such as cartilage repair (159), peripheral vascular diseases (160) or acute kidney injury (161). IGF-1 release with maintained bioactivity was shown in vitro using an injectable, thermo-sensitive hydrogel composite capable of gelling within $6 \mathrm{~s}$ (162). In this study, IGF-1 was also able to increase the survival of mesenchymal stem cells (MSCs) encapsulated in the gel, making the system an attractive strategy for cardiac tissue engineering. Collectively these studies provide evidence of how the combination of IGF-1 with therapeutic stem cells delivery is a promising approach to increase the survival and consequently the engraftment of transplanted cells. To date, there are no studies using injectable biomaterials to deliver IGF-1 as a single factor to the heart in vivo, but several reports of combined delivery which will be covered in the next section.

\section{Neuregulin-1 $\beta$}

Neuregulin-1 $\beta$ (NRG-1 $\beta$ ), a member of the epidermal growth factor (EGF) family, is another antiapoptotic factor that has recently gained attention as a therapy for cardiovascular diseases. The critical role of NRG-1 $\beta$ in both cardiac development and maintenance of normal adult heart function is wellestablished (163). NRG-1 $\beta$ receptor is expressed by human cardiac ventricular fibroblasts and NRG-1 $\beta$ treatment of these cells under stress has a pro-survival action (164). Moreover, activation of the NRG-1 $\beta$ pathway induces the production of angiopoietin-2 (Ang-2) and brain-derived neurotrophic factor (BDNF), which have pro-angiogenic and pro-survival effects, respectively (164). Systemic administration of NRG has demonstrated efficacy in reducing fibrosis and improving LV function in cardiomyopathy animal models (165-167), leading to clinical trials employing daily infusion of high dose recombinant NRG, which showed a modest improvement in LV ejection fraction in comparison to placebo or low dose administration (168). However, this approach involves daily infusions and off-target exposure and therefore, novel clinically translatable strategies are being investigated. As an example, Cohen et al. developed a hydroxyethyl methacrylate (HEMA)based injectable hydrogel system to directly deliver NRG to the myocardial border zone in a rat MI model, and showed augmented cardiomyocyte mitotic activity, decreased apoptosis, and greatly enhanced LV function without off-target exposure (169). Other injectable systems that have been tested for NRG delivery include PLGA-microparticles, which showed increased ejection fraction and also improved angiogenesis when delivered with a percutaneous intramyocardial injection in rat (170) and porcine preclinical models of MI (171).

\section{IMMUNOMODULATORY BIOACTIVE MOLECULES}

Due to the role of excessive inflammation in exacerbating myocardial damage post-MI, a range of immunomodulatory strategies have been attempted in clinical as well as in experimental studies (55). Although current standard pharmacotherapy post-MI has potent immunomodulatory functions (172). systemic administration of these agents has 
so far shown little benefit, and adverse effects of systemic immunomodulation limit their clinical translation.

Local delivery using hydrogels may be a promising alternate strategy. Some naturally derived materials be intrinsically anti-inflammatory. For example, chitosan scavenges Reactive Oxygen Species (ROS) in vitro and in vivo, which could explain the improved cardiac function following chitosan hydrogel injection post-MI (173). High molecular weight Hyaluronic Acid (HA) is another material of natural origin with ROS-scavenging properties $(174,175)$. Recently, also a fully synthetic hydrogel made of polyglycerol sulfate-based PEG showed intrinsic antiinflammatory actions when tested in an in vitro model of osteoarthritis (176). However, for most biomaterials, either of natural or synthetic origin, loading of anti-inflammatory therapeutics is necessary to modulate the inflammatory cardiac microenvironment.

Anti-inflammatory cytokines share the same challenges for in vivo delivery as other bioactive factors, most prominently a short half-life. IL-10 is a pleiotropic cytokine with broad immunoregulatory and anti-inflammatory activities (177). Daily subcutaneous injection of IL-10 in a rat MI model resulted in significantly decreased expression of pro-inflammatory cytokines and reduced macrophages infiltration (178). Its half-life of only $2.7-4.5 \mathrm{~h}$ (179), however, means that high doses and repeated injections are needed, leading to increased risk of side effects and high treatment cost. To overcome these issues, an injectable coacervate hydrogel was recently implemented for the delivery of IL-10 combined with bFGF in a mouse model of acute MI (180). A single coacervate treatment of $500 \mathrm{ng}$ each of bFGF and IL-10 led to long-term synergistic benefit post-MI with ameliorated LV contractile function and LV dilation. IL-2 and IL-19 have also proven beneficial against post-MI remodeling when delivered exogenously (181), (182). IL-2 is important for the survival of regulatory $\mathrm{T}$ cells, whereas IL-19 inhibits proinflammatory macrophages, making them promising candidates for incorporation into injectable biomaterial systems.

Besides the delivery of exogenous anti-inflammatory factors, inhibition of endogenous pro-inflammatory molecules may also achieve immunomodulation. Tumor necrosis factor (TNF)- $\alpha$ antagonism ameliorates ischemia/reperfusion injury (183) and hydrogels delivering anti-TNF- $\alpha$ have been used for several applications such as burns (184), wound healing (185) or inflammatory bowel disease (IBD) (186). Therefore, a therapeutic strategy using the same approach to salvage myocardial tissue post-MI could be promising.

An emerging and translationally relevant therapeutic approach to mitigate post-MI inflammation and remodeling involves the localized augmentation of Tissue Inhibitor of Metalloproteinases-3 (TIMP-3), a negative regulator of matrix metalloproteinase (MMP) activity. The cause-effect relationship between MMP induction and adverse LV remodeling has been established through pharmacological MMP inhibition (187). However, translation of systemic administration of MMP inhibitors has encountered concerns around potential off-target side effects when the delivery is not localized (188). Injectable hydrogels represent an attractive alternate means of delivery for TIMP-3. After the first proof of concept showing that sustained regional delivery of TIMP-3 through a degradable hyaluronic acid hydrogel can effectively block adverse LV remodeling $(189,190)$, the hydrogel was recently modified with an MMP-cleavable peptide (51). TIMP-3 release by this system was tested in pigs following coronary artery ligation, with promising results showing improved cardiac geometry and function (51). In all of the above studies, the favorable effects of TIMP- 3 on post-MI remodeling are associated with an attenuation of the local inflammatory process. TNF and TNF receptor mRNA were increased in all post-MI groups but were lower when delivering TIMP-3 in comparison to saline injection. The same trend was shown for markers of macrophages maturation and infiltration such as monocyte chemoattractant protein-1 (MCP-1) and macrophage inflammatory protein- $1 \alpha$ $($ MIP-1 $\alpha)$. Moreover, TIMP-3 release increased myofibroblast density, an index of a stronger and more flexible scar (191). This supports the notion that TIMP-3 improves LV geometry through modifying biological mediators of the adverse post-MI remodeling process (189).

Examples of anti-apoptotic and anti-inflammatory factors delivered in animal models are summarized in Table 2.

TABLE 2 | Exemplar injectable biomaterials used for the in vivo delivery of anti-apoptotic and anti-inflammatory bioactive molecules in animal models of MI.

\begin{tabular}{|c|c|c|c|c|c|c|}
\hline Biomaterial & $\begin{array}{l}\text { Growth } \\
\text { factor }\end{array}$ & $\begin{array}{l}\text { Induced } \\
\text { mechanism }\end{array}$ & $\begin{array}{l}\text { Animal } \\
\text { model }\end{array}$ & $\begin{array}{l}\text { Time of } \\
\text { administration }\end{array}$ & Outcome & References \\
\hline $\begin{array}{l}\text { Hydroxyethyl methacrylate } \\
\text { (HEMA) }\end{array}$ & Neuregulin-1 $\beta$ & $\begin{array}{l}\text { Anti- } \\
\text { apoptosis }\end{array}$ & Rat Ml & $\begin{array}{l}\text { Immediately } \\
\text { after MI }\end{array}$ & $\begin{array}{l}\text { Augmented cardiomyocytes mitotic activity and } \\
\text { decreased apoptosis. Improved cardiac } \\
\text { function with reduced left ventricular dilation }\end{array}$ & (169) \\
\hline $\begin{array}{l}\text { Poly(lactic-co-glycolic acid) } \\
\text { microparticles }\end{array}$ & Neuregulin-1 $\beta$ & $\begin{array}{l}\text { Anti- } \\
\text { apoptosis }\end{array}$ & $\begin{array}{l}\text { Swine } \\
\text { ischemia/ } \\
\text { reperfusion }\end{array}$ & $\begin{array}{l}1 \text { week post } \\
\mathrm{Ml}\end{array}$ & $\begin{array}{l}\text { Improvement in systolic and diastolic cardiac } \\
\text { function and decrease in transmural infarct } \\
\text { progression }\end{array}$ & $(171)$ \\
\hline Hyaluronic acid hydrogel & TIMP-3 & $\begin{array}{l}\text { Anti- } \\
\text { inflammatory }\end{array}$ & Swine Ml & $\begin{array}{l}\text { Immediately } \\
\text { after Ml }\end{array}$ & $\begin{array}{l}\text { Improved LV ejection fraction and reduced LV } \\
\text { dilation. Marked reduction in pro-inflammatory } \\
\text { cytokines }\end{array}$ & $(189)$ \\
\hline $\begin{array}{l}\text { Metalloproteinase- } \\
\text { responsive hyaluronic acid } \\
\text { hydrogel }\end{array}$ & TIMP-3 & $\begin{array}{l}\text { Anti- } \\
\text { inflammatory }\end{array}$ & Swine Ml & $\begin{array}{l}\text { Immediately } \\
\text { after MI }\end{array}$ & $\begin{array}{l}\text { Reduced LV dilation and wall thinning. } \\
\text { Decrease in transcriptional profile for } \\
\text { pro-fibrotic pathways }\end{array}$ & $(51)$ \\
\hline
\end{tabular}




\section{COMBINED DELIVERY OF MULTIPLE GROWTH FACTORS}

It is likely that a synergistic approach with simultaneous administration of multiple factors may more accurately mimic their natural mode of action and show more robust beneficial effects. Further, incorporation of multiple agents in an optimized ratio may allow for spatiotemporally controlled sequential delivery of several bioactive factors with synergistic effects.

The PEG-fibrinogen hydrogel described above (109) was also used for a dual delivery of VEGF and angiopoietin-1 (Ang1 ), another growth factor known to induce angiogenesis and maturation of newly formed blood vessels both in vitro (192) and in vivo $(193,194)$. The study demonstrated significant improvement in cardiac function at 4 weeks in rats treated with this combination of factors (195).

VEGF was also combined with HGF in a bioactive hydrogel comprising PEG linked to a protease-degradable peptide to take advantage of the high levels of proteases found in the ischemic myocardium (196). This stimulus-responsive system triggers the release of the encapsulated factors when remodeling occurs, and it was tested in a rat model of MI (197). Interestingly, when cardiac function was measured at day 7 post MI, only the empty hydrogel showed a significant improvement in function, as measured by fractional shortening. Conversely, at day 21 there was a significant improvement in function only in the group that received the hydrogel with the combination of factors (197). This suggests that VEGF and HGF are not released fast enough to have an effect in the acute phases, but they were efficient in inhibiting fibrosis and inducing angiogenesis at later time points and only if administered together.

Another common approach is to couple VEGF with other factors such as platelet-derived growth factors (PDGF-BB) that support the stability and the connectivity of new vessels by recruiting smooth muscle cells (198). PDGF signaling plays an essential role in cardiovascular development (199) and in both mouse and humans the PDGF family consists of four ligands, PGDF-A-D. However, only PDGF-A and PDGF$B$ are capable of forming functional heterodimers (199) and have been shown to protect cardiomyocytes from apoptosis and improving contractile function of an engineered heart tissue (200). VEGF 165 and PDGF-BB have been co-delivered through an alginate hydrogel, leading to improvements in cardiac function more than with each factor separately (198). Moreover, endothelial cells promote cardiomyocytes survival via PDGF signaling (201). A recent proangiogenic combination strategy involved the delivery of Stromal Derived Factor-1 (SDF1) and an angiogenic small tetrapeptide (Ac-SDKP) for bone marrow stem cell recruitment and angiogenesis, respectively (36). It showed how dual therapeutic factors can provide an injectable 3D microenvironment for recruiting MSCs into the ischemic area and, at the same time, play a role for stimulating neoangiogenesis.

IGF-1 has been coupled with several other factors for dual delivery and tested in vivo in MI models. Sequential delivery of regenerative factors is thought to be more effective than simultaneous delivery because it mimics the naturally-occurring healing phases (47). Alginate hydrogels were used for the sequential delivery of IGF-1 and HGF (202) in a rat model of MI. To increase the local potency of the factors at the infarct exploiting a localized stimulus, the delivery was carried out in a partially-crosslinked alginate solution, previously shown to undergo gelation in response to the high concentration of calcium ions that characterize the ischemic myocardium. The alginate hydrogel formed in situ, creating a local reservoir for the factors and providing an additional barrier against protein diffusion (202). The sequential release was achieved by varying the initial loading concentrations of the two factors. The study showed attenuated infarct expansion and diminished fibrosis, together with enhanced angiogenesis at the infarct site following dual delivery.

Furthermore, dual delivery of IGF-1 and VEGF was implemented in a study using injectable gelatin microspheres in a rat MI model (203). This showed how the neoangiogenesis promoted by VEGF can potentiate the anti-apoptotic actions of IGF-1, resulting in a marked reduction of infarct size associated with improved cardiac function. Nelson et al. encapsulated both IGF-1 and bFGF in a thermo-responsive synthetic hydrogel made of Poly(NIPAAm-co-HEMA-coMAPLA) (47) and previously described (204). Interestingly, cardiac function in the hydrogeltreated animals was improved at the 16 weeks timepoint compared to saline injection. However, both functional and histological evaluation showed no further benefit with the encapsulation of the factors compared to the empty gel (47). This could be due to the late time point chosen for gel injection in this study ( 2 weeks post-MI), since IGF-1 is more effective in preventing apoptosis in the early phases after an infarction (205). The material used in this study had a slow in vivo degradation rate (4-5 month); while the gold-standard for in situ degradation timing is still debated, a material designed to provide mechanical support should have a degradation time longer than 2 months $(47,206)$. The improvement shown in this study, regardless of factors incorporation, could then be explained by the long degradation rate, which allowed a slow shift of loadbearing responsibilities to the newly formed tissue. Moreover, a slow-degrading material remains in the tissue for enough time to support cell recruitment at the injection site, contributing to the overall success of the approach. Notably, macrophage infiltration to the site of injury was still significant 16 weeks after hydrogel injection (47). The majority of these cells stained positive for CD163, a scavenger receptor specifically expressed on the surface of activated anti-inflammatory macrophages and monocytes (207).

A combination of IGF-1 and bFGF increased ejection fraction and reduced pathological hypertrophy when delivered through a $\mathrm{pH}$-switchable hydrogel ${ }^{[49]}$ in a porcine model of chronic MI with catheter-based state of the art technology (208). These results are particularly promising not only for the use of a highly translatable delivery system in a large animal model but also due to the time of injection (4 weeks post-MI) which has clinical relevance for chronic MI in patients. A synergistic effect of stromal-derived factor-1 (SDF-1) and the small angiogenic tetra peptide Ac-SDKP was demonstrated in a rat chronic $\mathrm{MI}$ model using an injectable biomimetic 
hyaluronic acid hydrogel for the dual delivery to the heart (36). SDF-1 increases cardiomyocyte survival in the infarct zone and promotes stem cells mobilization and stabilization $(209,210)$. Examples of dual delivery approaches tested in vivo in animal models are summarized in Table 3. Recently, Awada et al. demonstrated that proper spatial and temporal cues from proteins are essential by using for the first time a combination of three complementary factors, TIMP-3, bFGF, and SDF- $1 \alpha$ embedded in heparin-based coacervates for sustained release regulated in a timely fashion (211). TIMP-3 reduced ECM degradation early after MI, while bFGF and SDF- $1 \alpha$ triggered a robust angiogenic process and progenitor cell recruitment over an 8 weeks period (211). A recent trend involves the delivery of a cocktail of stem cell-derived bioactive molecules known as secretome, which includes cytokines, growth factors, and exosomes. A nanocomposite injectable hydrogel loaded with secretome from human adipose-derived stem cell has been tested for its regenerative potential in vitro and in vivo in an acute MI rat model (212). The injection of the secretome-loaded hydrogel in the peri-infarct area provided cardioprotection promoting increased angiogenesis and reduction of cardiac remodeling (212). In summary, a successful outcome of this approach is dependent upon the choice of the right growth factors, in the right combination and at the right concentration.

A different strategy involves the use of injectable hydrogel for the delivery of RNAi molecules such as siRNA, miRNA, and shRNA to boost regeneration. RNAi molecules have a short half-life and are rapidly cleared if delivered systemically (213). Therefore, as bioactive factors, they could highly benefit from a localized and controlled delivery, as reviewed in Wang and Burdick (213). Although the field is still in its infancy, some recent applications for cardiac repair have already shown promising results (214-216).

TABLE 3 | Exemplar injectable biomaterials used for the in vivo combined delivery of multiple bioactive factors in animal models of Ml.

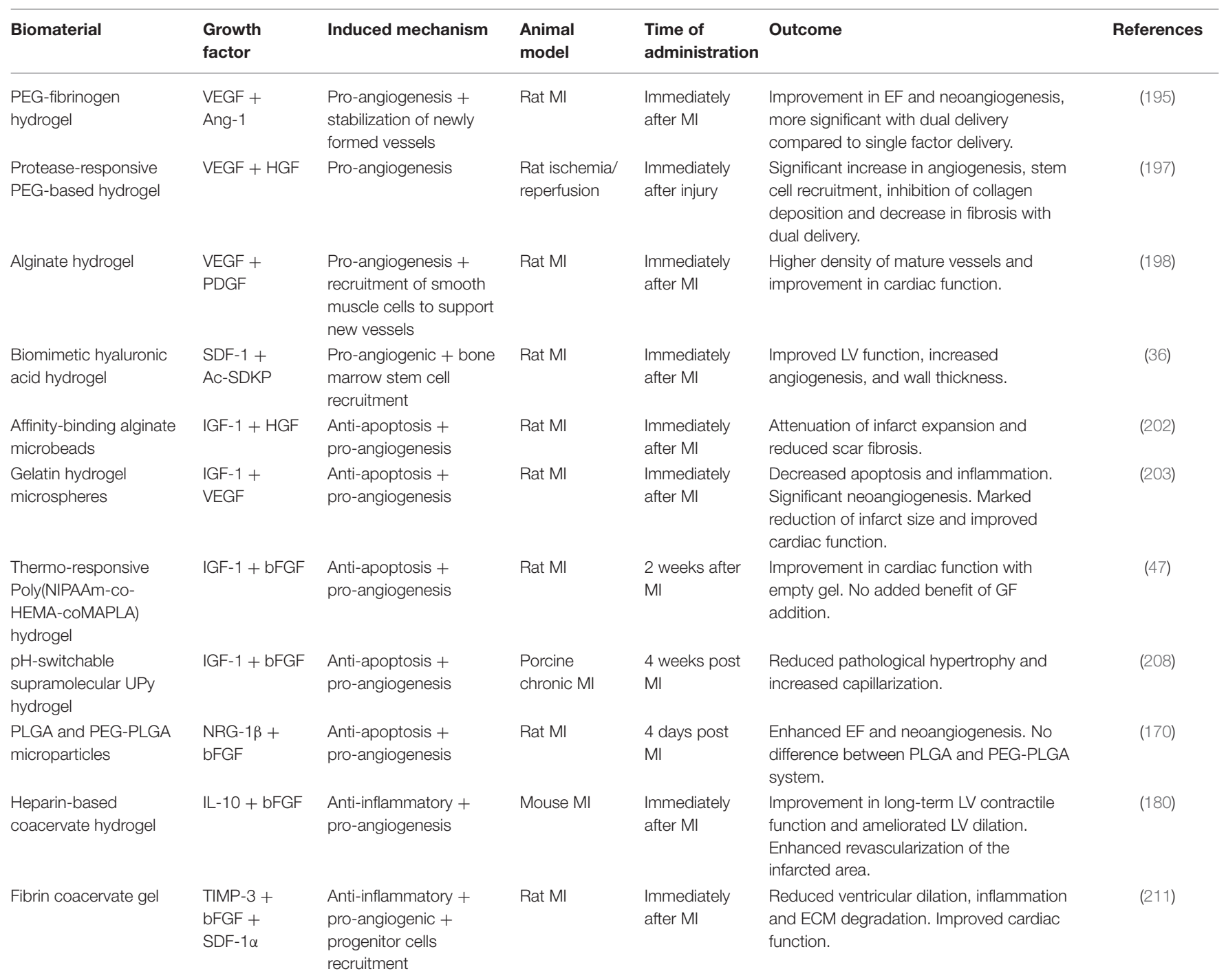




\section{CHALLENGES AND CLINICAL PERSPECTIVES}

The physical and biological properties of the injected material, together with timing and location of injections and distribution of the hydrogel in the cardiac wall are some of the parameters that may contribute to a successful post-MI treatment.

A consensus should be reached on what is considered a successful outcome for an injectable biomaterial study and what is the best parameter, or parameter combination, to focus on. In the studies presented in this review, wall thickness, fractional shortening, LV volumes, ejection fraction, infarct size, and vascularization of the infarct have all been considered. In the clinical setting, End Systolic Volume (ESV) has been shown to be the best predictor of survival and re-hospitalization (217). Specific considerations for myocardial applications are:

\section{Immunomodulatory Aspects}

Timing and location are crucial for the control of inflammation in the damaged heart. As we gain a more detailed understanding of the shifting post-MI immune response, an equally dynamic therapeutic protocol would engage a spectrum of immunomodulatory interventions during the post-MI period. Targeted delivery of these therapeutic agents is equally critical: although clinical trials involving immunomodulation use broad immunosuppressive protocols that have proven partially successful, a more localized dispatch of commonly used immunosuppressive treatments in the heart may greatly improve their immunomodulatory efficacy while minimizing systemic adverse effects. While production of engineered materials has historically been focused on maximizing their bioinert properties, recent studies reflect a shift toward active biomaterials that elicit a controlled inflammatory response as described above. Although several considerations are necessary when designing an injectable hydrogel, alginate hydrogels have already been used in clinical settings (218). However, one disadvantage of these materials is that they might retain some surface antigens capable to elicit an immune response. Conversely, synthetic materials are designed with defined chemical compositions that does not elicit a foreign body response, but often require functionalization with appropriate bioactive molecules to support cell attachment and survival. In the future, hydrogels with natural-synthetic hybrid compositions may allow more precise delivery of immunomodulatory biologics at the right place and time.

\section{Effects on the Cardiac Conduction System}

A significant concern when injecting a hydrogel into the myocardial wall is its possible effect on the cardiac conduction system. This is particularly important for patients eligible for a biomaterial therapy who may already have an increased risk of developing ventricular arrhythmias (219). Suarez et al. used optical mapping to study the effect of interstitial spread with PEG-based hydrogels in rats and did not observe changes to action potential propagation with high spreading materials characterized by slow gelation times (219). Conversely, materials with a quicker gelation time that form a bolus could potentially be a substrate for arrhythmias (219). This interesting study about a material design criterion that is often overlooked needs to be repeated in large animal models and with other biomaterials to provide better foundations for safer clinical use of injectable hydrogels.

\section{Biodegradability}

Degradation time of a hydrogel is a key parameter but data about biodegradability in vivo are still lacking. For myocardial tissue engineering, a material is considered biodegradable if degradation occurs through hydrolytic or enzymatic activity in vivo and if the degradation products comply with the requirements of both biodegradability and biocompatibility (29). In general, a material should persist long enough to have the desired effect but not longer than necessary to affect the repair process. Therefore, biomaterials designed for delivery of bioactive factors should persist in vivo for at least 1 week since most of the cell death occurs within the first few days after MI and should be fully degraded in 6-8 weeks. Materials of natural origin such as ECM-derived materials provide the correct composition to allow cell adhesion and survival and are degraded within days to weeks by enzymes produced by the cells into biodegradable and biocompatible products. Given the extensive research conducted in small animal models, the next step for a better in vivo characterization of biodegradability will require studies in large animal models, and longer-term follow-up to delineate the mechanisms in which these materials act, both biologically and mechanically.

\section{CONCLUSIONS}

Numerous preclinical studies on hydrogel-mediated delivery of bioactive factors to the heart have shown therapeutic benefit in terms of global cardiac parameters such as improved or maintained left ventricular geometry and ejection fraction. It is now widely acknowledged that the mechanism of action of successful cell therapy for cardiac repair occurs via paracrine signaling (220). Amplifying this therapeutic approach by local hydrogel-mediated delivery of salutary factors to improve cell survival, vascularisation and prevent excessive inflammation represents a promising avenue that could accelerate the development of novel treatment for MI and HF. The field of controlled-release systems through biomaterials is still in its infancy but offers significant potential to modulate immune response, modulate inflammation, and minimize infarct scar, promote angiogenesis to prevent cell death, and provide the necessary extracellular milieu for constructive cardiac remodeling after injury.

\section{AUTHOR CONTRIBUTIONS}

AF conceived and drafted the manuscript. SS contributed to the writing and the editing. SS, MS, and NR critically revised the work. All authors were responsible for the final approval of the completed version.

\section{ACKNOWLEDGMENTS}

We gratefully acknowledge the British Heart Foundation Center of Research Excellence for funding (RE/13/430184). 


\section{REFERENCES}

1. Roth GA, Johnson C, Abajobir A, Abd-Allah F, Abera SF, Abyu G, et al. Global, regional, and national burden of cardiovascular diseases for 10 causes, 1990 to 2015. J Am Coll Cardiol. (2017) 70:1-25. doi: 10.1016/j.jacc.2017.04.052

2. Townsend N, Nichols M, Scarborough P, Rayner M. Cardiovascular disease in Europe - epidemiological update 2015. Eur Heart J. (2015) 36:2696-705. doi: 10.1093/eurheartj/ehv428

3. Lundy SD, Gantz JA, Pagan CM, Filice D, Laflamme MA. Pluripotent stem cell derived cardiomyocytes for cardiac repair. Curr Treat Opt Cardiovasc Med. (2014) 16:319. doi: 10.1007/s11936-014-0319-0

4. Heineke J, Molkentin JD. Regulation of cardiac hypertrophy by intracellular signalling pathways. Nat Rev Mol Cell Biol. (2006) 7:589. doi: $10.1038 / \mathrm{nrm} 1983$

5. Frangogiannis NG. The immune system and the remodeling infarcted heart: cell biological insights and therapeutic opportunities. J Cardiovasc Pharmacol. (2014) 63:185-95. doi: 10.1097/FJC.0000000000000003

6. Prabhu SD, Frangogiannis NG. The biological basis for cardiac repair after myocardial infarction: from inflammation to fibrosis. Circ Res. (2016) 119:91-112. doi: 10.1161/CIRCRESAHA.116.303577

7. Fildes JE, Shaw SM, Yonan N, Williams SG. The immune system and chronic heart failure: is the heart in control? J Am Coll Cardiol. (2009) 53:1013-20. doi: 10.1016/j.jacc.2008.11.046

8. Sattler S, Fairchild P, Watt FM, Rosenthal N, Harding SE. The adaptive immune response to cardiac injury-the true roadblock to effective regenerative therapies? NPJ Regen Med. (2017) 2:19. doi: 10.1038/s41536-017-0022-3

9. Hansson EM, Lindsay ME, Chien KR. Regeneration next: toward heart stem cell therapeutics. Cell Stem Cell. (2009) 5:364-77. doi: 10.1016/j.stem.2009.09.004

10. Mitter SS, Yancy CW. Contemporary approaches to patients with heart failure. Cardiol Clin. (2017) 35:261-71. doi: 10.1016/j.ccl.2016.12.008

11. Inamdar A, Inamdar A. Heart failure: diagnosis, management and utilization. J Clin Med. (2016) 5:62. doi: 10.3390/jcm5070062

12. Riley JP, Beattie JM. Palliative care in heart failure: facts and numbers. ESC Heart Fail. (2016) 4:81-7. doi: 10.1002/ehf2.12125

13. Hsich EM. Matching the market for heart transplantation. Circ Heart Failure. (2016) 9:e002679. doi: 10.1161/CIRCHEARTFAILURE.115.002679

14. Lund LH, Edwards LB, Kucheryavaya AY, Dipchand AI, Benden C, Christie JD, et al. The registry of the international society for heart and lung transplantation: thirtieth official adult heart transplant report-2013; Focus Theme: Age. J Heart Lung Transpl. (2013) 32:951-64. doi: 10.1016/j.healun.2013.08.006

15. Garbade J, Barten MJ, Bittner HB, Mohr FW. Heart transplantation and left ventricular assist device therapy: two comparable options in end-stage heart failure? Clin Cardiol. (2013) 36:378-82. doi: 10.1002/clc.22124

16. Sheikh AY, Lin SA, Cao F, Cao Y, van der Bogt KE, Chu P, et al. Molecular imaging of bone marrow mononuclear cell homing and engraftment in ischemic myocardium. Stem Cells. (2007) 25:2677-84. doi: 10.1634/stemcells.2007-0041

17. Freyman T, Polin G, Osman H, Crary J, Lu M, Cheng L, et al. A quantitative, randomized study evaluating three methods of mesenchymal stem cell delivery following myocardial infarction. Eur Heart J. (2006) 27:1114-22. doi: 10.1093/eurheartj/ehi818

18. van den Akker F, Feyen DA, van den Hoogen P, van Laake LW, van Eeuwijk EC, Hoefer I, et al. Intramyocardial stem cell injection: go(ne) with the flow. Eur Heart J. (2017) 38:184-6. doi: 10.1093/eurheartj/ehw056

19. Peña B, Laughter M, Jett S, Rowland TJ, Taylor RG, Mestroni L, et al. Injectable hydrogels for cardiac tissue engineering. Macromol Biosci. (2018) 18:1800079. doi: 10.1002/mabi.201800079

20. Blom AS, Pilla JJ, Gorman RC, Gorman JH, Mukherjee R, Spinale FG, et al. Infarct size reduction and attenuation of global left ventricular remodeling with the CorCapTM Cardiac support device following acute myocardial infarction in sheep. Heart Fail Rev. (2005) 10:125-39. doi: 10.1007/s10741-005-4640-2

21. Enomoto Y, Gorman JH, Moainie SL, Jackson BM, Parish LM, Plappert T, et al. Early ventricular restraint after myocardial infarction: extent of the wrap determines the outcome of remodeling. Ann Thorac Surg. (2005) 79:881-7. doi: 10.1016/j.athoracsur.2004.05.072
22. Pilla JJ, Blom AS, Gorman JH, Brockman DJ, Affuso J, Parish LM, et al. Early postinfarction ventricular restraint improves borderzone wall thickening dynamics during remodeling. Ann Thorac Surg. (2005) 80:225762. doi: 10.1016/j.athoracsur.2005.05.089

23. Tous E, Purcell B, Ifkovits JL, Burdick JA. Injectable acellular hydrogels for cardiac repair. J Cardiovasc Translat Res. (2011) 4:528-42. doi: 10.1007/s12265-011-9291-1

24. Pena B, Martinelli V, Jeong M, Bosi S, Lapasin R, Taylor MR, et al. Biomimetic polymers for cardiac tissue engineering. Biomacromolecules. (2016) 17:1593601. doi: 10.1021/acs.biomac.5b01734

25. Hasan A, Khattab A, Islam MA, Hweij KA, Zeitouny J, Waters R, et al. Injectable hydrogels for cardiac tissue repair after myocardial infarction. Adv Sci. (2015) 21:500122. doi: 10.1002/advs.201500122

26. Ye Z, Zhou Y, Cai H, Tan W. Myocardial regeneration: roles of stem cells and hydrogels. Adv Drug Deliv Rev. (2011) 63:688-97. doi: 10.1016/j.addr.2011.02.007

27. Johnson TD, Christman KL. Injectable hydrogel therapies and their delivery strategies for treating myocardial infarction. Exp Opin Drug Deliv. (2013) 10:59-72. doi: 10.1517/17425247.2013.739156

28. Shapira-Schweitzer K, Habib M, Gepstein L, Seliktar D. A photopolymerizable hydrogel for 3-D culture of human embryonic stem cell-derived cardiomyocytes and rat neonatal cardiac cells. J Mol Cell Cardiol. (2009) 46:213-24. doi: 10.1016/j.yjmcc.2008.10.018

29. Reis LA, L.Chiu LY, Feric N, Fu L, Radisic M. Biomaterials in myocardial tissue engineering. J Tissue Eng Regenerat Med. (2016) 10:11-28. doi: 10.1002/term.1944

30. Vunjak-Novakovic G, Tandon N, Godier A, Maidhof R, Marsano A, Martens TP, et al. Challenges in cardiac tissue engineering. Tissue Eng Part B Rev. (2010) 16:169-87. doi: 10.1089/ten.teb.2009.0352

31. Gyöngyösi M, Dib N. Diagnostic and prognostic value of $3 \mathrm{D}$ NOGA mapping in ischemic heart disease. Nat Rev Cardiol. (2011) 8:393. doi: $10.1038 /$ nrcardio. 2011.64

32. Omens JH. Stress and strain as regulators of myocardial growth. Prog Biophys Mol Biol. (1998) 69:559-72. doi: 10.1016/S0079-6107(98)00025-X

33. Venugopal JR, Prabhakaran MP, Mukherjee S, Ravichandran R, Dan K, Ramakrishna S. Biomaterial strategies for alleviation of myocardial infarction. J R Soc Interface. (2012) 9:1-19. doi: 10.1098/rsif.2011.0301

34. Berry MF, Engler AJ, Woo YJ, Pirolli TJ, Bish LT, Jayasankar V, et al. Mesenchymal stem cell injection after myocardial infarction improves myocardial compliance. Am J Physiol Heart Circ Physiol. (2006) 290:H2196203. doi: 10.1152/ajpheart.01017.2005

35. Zhang S, Sun A, Liang Y, Chen Q, Zhang C, Wang K,et al. A role of myocardial stiffness in cell-based cardiac repair: a hypothesis. J Cell Mol Med. (2009) 13:660-3. doi: 10.1111/j.1582-4934.2009.00710.x

36. Song M, Jang H, Lee J, Kim JH, Kim SH, Sun K, et al. Regeneration of chronic myocardial infarction by injectable hydrogels containing stem cell homing factor SDF-1 and angiogenic peptide Ac-SDKP. Biomaterials. (2014) 35:2436-45. doi: 10.1016/j.biomaterials.2013.12.011

37. Landa N, Miller L, Feinberg MS, Holbova R, Shachar M, Freeman I, et al. Effect of injectable alginate implant on cardiac remodeling and function after recent and old infarcts in rat. Circulation. (2008) 117:1388-96. doi: 10.1161/CIRCULATIONAHA.107.727420

38. Blackburn NJ, Sofrenovic T, Kuraitis D, Ahmadi A, McNeill B, Deng C, et al. Timing underpins the benefits associated with injectable collagen biomaterial therapy for the treatment of myocardial infarction. Biomaterials. (2015) 39:182-92. doi: 10.1016/j.biomaterials.2014.11.004

39. Ifkovits JL, Tous E, Minakawa M, Morita M, Robb JD, Koomalsingh KJ, et al. Injectable hydrogel properties influence infarct expansion and extent of postinfarction left ventricular remodeling in an ovine model. Proc Natl Acad Sci USA. (2010) 107:11507-12. doi: 10.1073/pnas.1004097107

40. Shen D, Wang X, Zhang L, Zhao X, Li J, Cheng K, et al. The amelioration of cardiac dysfunction after myocardial infarction by the injection of keratin biomaterials derived from human hair. Biomaterials. (2011) 32:9290-9. doi: 10.1016/j.biomaterials.2011.08.057

41. Okada M, Payne TR, Oshima H, Momoi N, Tobita K, Huard J. Differential efficacy of gels derived from small intestinal submucosa as an injectable biomaterial for myocardial infarct repair. Biomaterials. (2010) 31:7678-83. doi: 10.1016/j.biomaterials.2010.06.056

42. Dai W, Wold LE, Dow JS, Kloner RA. Thickening of the infarcted wall by collagen injection improves left ventricular function in rats: a novel approach 
to preserve cardiac function after myocardial infarction. J Am Coll Cardiol. (2005) 46:714-9. doi: 10.1016/j.jacc.2005.04.056

43. Lister Z, Rayner KJ, Suuronen EJ. How biomaterials can influence various cell types in the repair and regeneration of the heart after myocardial infarction. Front Bioeng Biotechnol. (2016) 4:62. doi: 10.3389/fbioe.2016.00062

44. Forte E, Furtado MB, Rosenthal N. The interstitium in cardiac repair: role of the immune-stromal cell interplay. Nat Rev Cardiol. (2018) 15:601-16. doi: 10.1038/s41569-018-0077-x

45. Priya James H, John R, Alex A, Anoop KR. Smart polymers for the controlled delivery of drugs - a concise overview. Acta Pharm Sin B. (2014) 4:120-7. doi: 10.1016/j.apsb.2014.02.005

46. Sood N, Bhardwaj A, Mehta S, Mehta A. Stimuli-responsive hydrogels in drug delivery and tissue engineering. Drug Deliv. (2016) 23:748-70. doi: 10.3109/10717544.2014.940091

47. Nelson DM, Hashizume R, Yoshizumi T, Blakney AK, Ma Z, Wagner WR. Intramyocardial injection of a synthetic hydrogel with delivery of bFGF and IGF1 in a rat model of ischemic cardiomyopathy. Biomacromolecules. (2014) 15:1-11. doi: 10.1021/bm4010639

48. Fujimoto KL, Ma Z, Nelson DM, Hashizume R, Guan J, Tobita $\mathrm{K}$, et al. Synthesis, characterization and therapeutic efficacy of a biodegradable, thermoresponsive hydrogel designed for application in chronic infarcted myocardium. Biomaterials. (2009) 30:4357-68. doi: 10.1016/j.biomaterials.2009.04.055

49. M.Bastings MC, Koudstaal S, Kieltyka RE, Nakano Y, Pape CH, Feyen $\mathrm{AM}$, et al. A Fast $\mathrm{pH}$-switchable and self-healing supramolecular hydrogel carrier for guided, local catheter injection in the infarcted myocardium. Adv Healthcare Mater. (2013) 3:70-8. doi: 10.1002/adhm.201300076

50. Garbern JC, Hoffman AS, Stayton PS. Injectable pH- and temperatureresponsive poly $(\mathrm{N}$-isopropylacrylamide-co-propylacrylic acid) copolymers for delivery of angiogenic growth factors. Biomacromolecules. (2010) 11:1833-9. doi: 10.1021/bm100318z

51. Purcell BP, Barlow SC, Perreault PE, Freeburg L, Doviak H, Jacobs J, et al. Delivery of a matrix metalloproteinase-responsive hydrogel releasing TIMP-3 after myocardial infarction: effects on left ventricular remodeling. Am J Physiol Heart Circ Physiol. (2018) 315:H814-25. doi: 10.1152/ajpheart.00076.2018

52. Wu J, Zeng F, Huang P, Chung CY, Konecny F, Weisel RDR, et al. Infarct stabilization and cardiac repair with a VEGF-conjugated, injectable hydrogel. Biomaterials. (2011) 32:579-86. doi: 10.1016/j.biomaterials.2010.08.098

53. Chung HJ, Sulkin MS, Kim JS, Goudeseune C, Chao HY, Song JW, et al. Stretchable, multiplexed $\mathrm{pH}$ sensors with demonstrations on rabbit and human hearts undergoing ischemia. Adv Healthcare Mater. (2014) 3:59-68. doi: $10.1002 / \mathrm{adhm} .201300124$

54. Rajamäki K, Nordström T, Nurmi K, K.Åkerman EO, Kovanen PT, Öörni $\mathrm{K}$, et al. Extracellular acidosis is a novel danger signal alerting innate immunity via the NLRP3 inflammasome. J Biol Chem. (2013) 288:13410-9. doi: $10.1074 /$ jbc.M112.426254

55. Panahi M, Papanikolaou A, Torabi A, Zhang G, Khan H, Vazir A, et al. Immunomodulatory interventions in myocardial infarction and heart failure: a systematic review of clinical trials and meta-analysis of IL-1 inhibition. Cardiovasc Res. (2018) 114:1445-61. doi: 10.1093/cvr/cvy145

56. Sager HB, Heidt T, Hulsmans M, Dutta P, Courties G, Sebas $\mathrm{M}$, et al. Targeting Interleukin-1 $\beta$ Reduces Leukocyte Production After Acute Myocardial Infarction. Circulation. (2015) 132:1880-90. doi: 10.1161/CIRCULATIONAHA.115.016160

57. Toldo S, Van Tassell BW, Abbate A. Interleukin-1 blockade in acute myocardial infarction and heart failure: getting closer and closer. JACC Basic Transl Sci. (2017) 2:431-3. doi: 10.1016/j.jacbts.2017.07.006

58. Schirmer L, Atallah P, Werner C, Freudenberg U. StarPEG-heparin hydrogels to protect and sustainably deliver IL-4. Adv Healthcare Mater. (2016) 5:3157-64. doi: 10.1002/adhm.201600797

59. Langer R, Folkman J. Polymers for the sustained release of proteins and other macromolecules. Nature. (1976) 263:797-800.

60. Johnson NR, Wang Y. Coacervate delivery systems for proteins and small molecule drugs. Exp Opin Drug Deliv. (2014) 11:1829-32. doi: 10.1517/17425247.2014.941355

61. Awada HK, Hwang MP, Wang Y. Towards comprehensive cardiac repair and regeneration after myocardial infarction: aspects to consider and proteins to deliver. Biomaterials. (2016) 82:94-112. doi: $10.1016 /$ j.biomaterials.2015.12.025
62. Williams DF. Definitions in biomaterials. In: Proceedings of a Consensus Conference of the European Society for Biomaterials. Chester; Amsterdam; New York, NY: Elsevier (1987).

63. Williams DF. There is no such thing as a biocompatible material. Biomaterials. (2014) 35:10009-14. doi: 10.1016/j.biomaterials.2014.08.035

64. Browne S, Pandit A. Biomaterial-mediated modification of the local inflammatory environment. Front Bioeng Biotechnol. (2015) 3:67. doi: 10.3389/fbioe.2015.00067

65. Brown BN, Valentin JE, Stewart-Akers AM, McCabe GP, Badylak SF. Macrophage phenotype and remodeling outcomes in response to biologic scaffolds with and without a cellular component. Biomaterials. (2009) 30:1482-91. doi: 10.1016/j.biomaterials.2008.11.040

66. Badylak SF, Valentin JE, Ravindra AK, McCabe GP, Stewart-Akers AM. Macrophage phenotype as a determinant of biologic scaffold remodeling. Tissue Eng Part A. (2008) 14:1835-42. doi: 10.1089/ten.tea.2007.0264

67. Grotenhuis N, Bayon Y, Lange JF, Van Osch VM, Bastiaansen-Jenniskens YM. A culture model to analyze the acute biomaterial-dependent reaction of human primary macrophages. Biochem Biophys Res Commun. (2013) 433:115-20. doi: 10.1016/j.bbrc.2013.02.054

68. Garg K, Pullen NA, Oskeritzian CA, Ryan JJ, Bowlin GL. Macrophage functional polarization $(\mathrm{m} 1 / \mathrm{m} 2)$ in response to varying fiber and pore dimensions of electrospun scaffolds. Biomaterials. (2013) 34:4439-51. doi: 10.1016/j.biomaterials.2013.02.065

69. Wang Z, Cui Y, Wang J, Yang X, Wu Y, Wang K, et al. The effect of thick fibers and large pores of electrospun poly( $\varepsilon$-caprolactone) vascular grafts on macrophage polarization and arterial regeneration. Biomaterials. (2014) 35:5700-10. doi: 10.1016/j.biomaterials.2014.03.078

70. Jiang XJ, Wang T, Li XY, Wu DQ, Zheng ZB, Zhang JF, et al. Injection of a novel synthetic hydrogel preserves left ventricle function after myocardial infarction. J Biomed Mater Res Part A. (2008) 90:472-7. doi: $10.1002 / j b m . a .32118$

71. Lee RJ, Hinson A, Bauernschmitt R, Matschke K, Fang Q, Mann DL, et al. The feasibility and safety of Algisyl-LVR ${ }^{\mathrm{TM}}$ as a method of left ventricular augmentation in patients with dilated cardiomyopathy: Initial first in man clinical results. Int J Cardiol. (2015) 199:18-24. doi: 10.1016/j.ijcard.2015.06.111

72. Lee LC, Wall ST, Klepach D, Ge L, Zhang Z, Lee RJ, et al. Algisyl-LVR ${ }^{\mathrm{TM}}$ with coronary artery bypass grafting reduces left ventricular wall stress and improves function in the failing human heart. Int J Cardiol. (2013) 168:2022-8. doi: 10.1016/j.ijcard.2013.01.003

73. Lee LC, Zhihong Z, Hinson A, Guccione JM. Reduction in left ventricular wall stress and improvement in function in failing hearts using Algisyl-LVR. J Vis Exp. (2013) 74:e50096. doi: 10.3791/50096

74. Shaikh FM, Callanan A, Kavanagh EG, Burke PE, Grace PA, McGloughlin TM. Fibrin: A natural biodegradable scaffold in vascular tissue engineering. Cells Tissues Organs. (2008) 188:333-46. doi: 10.1159/000139772

75. Christman KL, Fok HH, Sievers RE, Fang Q, Lee RJ. Fibrin Glue Alone and skeletal myoblasts in a fibrin scaffold preserve cardiac function after myocardial infarction. Tissue Eng. (2004) 10:403-9. doi: $10.1089 / 107632704323061762$

76. Christman KL, Vardanian AJ, Fang Q, Sievers RE, Fok HH, Lee RJ. Injectable fibrin scaffold improves cell transplant survival, reduces infarct expansion, and induces neovasculature formation in ischemic myocardium. J Am Coll Cardiol. (2004) 44:654-60. doi: 10.1016/j.jacc.2004.04.040

77. Sahni A, Odrljin T, Francis CW. Binding of basic fibroblast growth factor to fibrinogen and fibrin. J Biol Chem. (1998) 273:7554-9. doi: $10.1074 /$ jbc.273.13.7554

78. Singelyn JM, Sundaramurthy P, Johnson TD, Schup-Magoffin PJ, Hu DP, Faulk DM, et al. Catheter-deliverable hydrogel derived from decellularized ventricular extracellular matrix increases endogenous cardiomyocytes and preserves cardiac function post-myocardial infarction. J Am Coll Cardiol. (2012) 59:751-63. doi: 10.1016/j.jacc.201 1.10 .888

79. Seif-Naraghi SB, Singelyn JM, Salvatore MA, Osborn KG, Wang JJ, Sampat $\mathrm{U}$, et al. Safety and efficacy of an injectable extracellular matrix hydrogel for treating myocardial infarction. Sci Transl Med. (2013) 5:173ra25. doi: 10.1126/scitranslmed.3005503

80. Rowley JA, Madlambayan G, Mooney DJ. Alginate hydrogels as synthetic extracellular matrix materials. Biomaterials. (1999) 20:45-53. doi: 10.1016/S0142-9612(98)00107-0 
81. Jason Burdick A, Robert Mauck L, Gerecht S. To serve and protect: hydrogels to improve stem cell-based therapies. Cell Stem Cell. (2016) 18:13-15. doi: 10.1016/j.stem.2015.12.004

82. Leor J, Tuvia S, Guetta V, Manczur F, Castel D, Willenz U, et al. Intracoronary injection of in situ forming alginate hydrogel reverses left ventricular remodeling after myocardial infarction in swine. J Am Coll Cardiol. (2009) 54:1014-23. doi: 10.1016/j.jacc.2009.06.010

83. Tsur-Gang O, Ruvinov E, Landa N, Holbova R, Feinberg MS, Leor J, et al. The effects of peptide-based modification of alginate on left ventricular remodeling and function after myocardial infarction. Biomaterials. (2009) 30:189-95. doi: 10.1016/j.biomaterials.2008.09.018

84. Liberski A, Latif N, Raynaud C, Bollensdorff C, Yacoub M. Alginate for cardiac regeneration: From seaweed to clinical trials. Glob Cardiol Sci Pract. (2016) 2016:e201604. doi: 10.21542/gcsp.2016.4

85. Charalambous BM, Stephens RC, Feavers IM, Montgomery HE. Role of bacterial endotoxin in chronic heart failure: the gut of the matter. Shock. (2007) 28:15-23. doi: 10.1097/shk.0b013e318033ebc5

86. Anker SD, Coats AJS, Cristian G, Dragomir D, Pusineri E, Piredda M, et al. A prospective comparison of alginate-hydrogel with standard medical therapy to determine impact on functional capacity and clinical outcomes in patients with advanced heart failure (AUGMENT-HF trial). Eur Heart J. (2015) 36:2297-309. doi: 10.1093/eurheartj/ehv259

87. Wang $\mathrm{T}, \mathrm{Wu}$ DQ, Jiang XJ, Zhang XZ, Li XY, Zhang JF, et al. Novel thermosensitive hydrogel injection inhibits post-infarct ventricle remodelling. Eur J Heart Fail. (2009) 11:14-9. doi: 10.1093/eurjhf/hfn009

88. Fujimoto KL, Tobita K, Merryman WD, Guan J, Momoi N, Stolz $\mathrm{DB}$, et al. An elastic, biodegradable cardiac patch induces contractile smooth muscle and improves cardiac remodeling and function in subacute myocardial infarction. J Am Coll Cardiol. (2007) 49:2292-300. doi: $10.1016 /$ j.jacc.2007.02.050

89. Singla DK, Singla RD, Lamm S, Glass C. TGF- $\beta 2$ treatment enhances cytoprotective factors released from embryonic stem cells and inhibits apoptosis in infarcted myocardium. Am J Physiol Heart Circ Physiol. (2011) 300:H1442-50. doi: 10.1152/ajpheart.00917.2010

90. Wu SZ, Li YL, Huang W, Cai WF, Liang J, Paul C, et al. Paracrine effect of CXCR4-overexpressing mesenchymal stem cells on ischemic heart injury. Cell Biochem Funct. (2017) 35:113-23. doi: 10.1002/cbf.3254

91. Gnecchi M, He H, Noiseux N, Liang OD, Zhang L, Morello F, et al. Evidence supporting paracrine hypothesis for Akt-modified mesenchymal stem cellmediated cardiac protection and functional improvement. FASEB J. (2006) 20:661-9. doi: 10.1096/fj.05-5211com

92. Webber MJ, Han X, Murthy SNP, Rajangam K, Stupp SI, Lomasney JW. Capturing the stem cell paracrine effect using heparin-presenting nanofibres to treat cardiovascular diseases. J Tissue Eng Regenerat Med. (2010) 4:600-10. doi: $10.1002 /$ term.273

93. Zhao L, Liu X, Zhang Y, Liang X, Ding Y, Xu Y, et al. Enhanced cell survival and paracrine effects of mesenchymal stem cells overexpressing hepatocyte growth factor promote cardioprotection in myocardial infarction. Exp Cell Res. (2016) 344:30-9. doi: 10.1016/j.yexcr.2016.03.024

94. Mirotsou M, Jayawardena TM, Schmeckpeper J, Gnecchi M, Dzau VJ. Paracrine mechanisms of stem cell reparative and regenerative actions in the heart. J Mol Cell Cardiol. (2011) 50:280-9. doi: 10.1016/j.yjmcc.2010.08.005

95. Hodgkinson CP, Bareja A, Gomez JA, Dzau VJ. Emerging concepts in paracrine mechanisms in regenerative cardiovascular medicine and biology. Circ Res. (2016) 118:95-107. doi: 10.1161/CIRCRESAHA.115.305373

96. J.-Silvestre S, Menasché P. The evolution of the stem cell theory for heart failure. EBioMedicine. (2015) 2:1871-9. doi: 10.1016/j.ebiom.2015.11.010

97. Hausenloy DJ, Yellon DM. Cardioprotective growth factors. Cardiovasc Res. (2009) 83:179-94. doi: 10.1093/cvr/cvp062

98. Hwang H, Kloner RA. The combined administration of multiple soluble factors in the repair of chronically infarcted rat myocardium. J Cardiovasc Pharmacol. (2011) 57:282-6. doi: 10.1097/FJC.0b013e3182058717

99. de Rebouças JS, Santos-Magalhães NS, Formiga FR. Cardiac regeneration using growth factors: advances and challenges. Arq Bras Cardiol. (2016) 107:271-5. doi: 10.5935/abc.20160097

100. Simons M, Annex BH, Laham RJ, Kleiman N, Henry T, Dauerman H, et al. Pharmacological treatment of coronary artery disease with recombinant fibroblast growth factor-2: double-blind, randomized, controlled clinical trial. Circulation. (2002) 105:788-93. doi: 10.1161/hc0802.104407
101. Y.-Ng S, D'Amore PA. Therapeutic angiogenesis for cardiovascular disease. Curr Controlled Trials Cardiovasc Med. (2001) 2:278-85. doi: 10.1186/CVM-2-6-278

102. Cochain C, Channon KM, Silvestre JS. Angiogenesis in the infarcted myocardium. Antioxid Redox Signal. (2013) 18:1100-13. doi: 10.1089/ars.2012.4849

103. Epstein SE, Fuchs S, Zhou YF, Baffour R, Kornowski R. Therapeutic interventions for enhancing collateral development by administration of growth factors: basic principles, early results and potential hazards. Cardiovasc Res. (2001) 49:532-42. doi: 10.1016/S0008-6363(00)00217-0

104. Laham RJ, Rezaee M, Post M, Sellke FW, Braeckman RA, Hung D, et al. Intracoronary and intravenous administration of basic fibroblast growth factor: myocardial and tissue distribution. Drug Metab Disposit. (1999) 27:821.

105. Lee RJ, Springer ML, Blanco-Bose WE, Shaw R, Ursell PC, Blau HM. VEGF gene delivery to myocardium: deleterious effects of unregulated expression. Circulation. (2000) 102:898-901. doi: 10.1161/01.CIR.102.8.898

106. Horowitz Jeffrey $R$, Rivard $A$, van der Zee $R$, Hariawala $M$, Sheriff Don D, Esakof Darryl D, et al. Vascular endothelial growth factor/vascular permeability factor produces nitric oxide-dependent hypotension. Arterioscler Thromb Vasc Biol. (1997) 17:2793-800. doi: 10.1161/01.ATV.17.11.2793

107. Hariawala MD, Horowitz JR, Esakof D, Sheriff DD, Walter DH, Keyt $\mathrm{B}$, et al. VEGF improves myocardial blood flow but produces EDRFmediated hypotension in porcine hearts. J Surg Res. (1996) 63:77-82. doi: 10.1006/jsre.1996.0226

108. Unger EF, Goncalves L, Epstein SE, Chew EY, Trapnell CB, Cannon RO III, et al. Effects of a single intracoronary injection of basic fibroblast growth factor in stable angina pectoris. Am J Cardiol. (2000) 85:1414-9. doi: 10.1016/S0002-9149(00)00787-6

109. Rufaihah AJ, Vaibavi SR, Plotkin M, Shen J, Nithya V, Wang J, et al. Enhanced infarct stabilization and neovascularization mediated by VEGF-loaded PEGylated fibrinogen hydrogel in a rodent myocardial infarction model. Biomaterials. (2013) 34:8195-202. doi: 10.1016/j.biomaterials.2013.07.031

110. Yamamoto T, Suto N, Okubo T, Mikuniya A, Hanada H, Yagihashi S, et al. Intramyocardial delivery of basic fibroblast growth factor-impregnated gelatin hydrogel microspheres enhances collateral circulation to infarcted canine myocardium. Jpn Circ J. (2001) 65:439-44. doi: 10.1253/jcj.65.439

111. Li Z, Masumoto H, Jo J, Yamazaki K, Ikeda T, Tabata Y, et al. Sustained release of basic fibroblast growth factor using gelatin hydrogel improved left ventricular function through the alteration of collagen subtype in a rat chronic myocardial infarction model. Gen Thorac Cardiovasc Surg. (2018) 66:641-7. doi: 10.1007/s11748-018-0969-z

112. Kumagai M, Minakata K, Masumoto H, Yamamoto M, Yonezawa A, Ikeda $\mathrm{T}$, et al. A therapeutic angiogenesis of sustained release of basic fibroblast growth factor using biodegradable gelatin hydrogel sheets in a canine chronic myocardial infarction model. Heart Vessels. (2018) 33:1251-7. doi: 10.1007/s00380-018-1185-6

113. Wang H, Zhang X, Li Y, Ma Y, Zhang Y, Liu Z, et al. Improved myocardial performance in infarcted rat heart by co-injection of basic fibroblast growth factor with temperature-responsive chitosan hydrogel. J Heart Lung Transpl. (2010) 29:881-7. doi: 10.1016/j.healun.2010.03.016

114. Seif-Naraghi SB, Horn D, Schup-Magoffin PJ, Christman KL. Injectable extracellular matrix derived hydrogel provides a platform for enhanced retention and delivery of a heparin-binding growth factor. Acta Biomater. (2012) 8:3695-703. doi: 10.1016/j.actbio.2012.06.030

115. Zhu H, Li X, Yuan M, Wan W, Hu M, Wang X, et al. Intramyocardial delivery of bFGF with a biodegradable and thermosensitive hydrogel improves angiogenesis and cardio-protection in infarcted myocardium. Exp Therap Med. (2017) 14:3609-15. doi: 10.3892/etm.2017.5015

116. Garbern JC, Minami E, Stayton PS, Murry CE. Delivery of basic fibroblast growth factor with a $\mathrm{pH}$-responsive, injectable hydrogel to improve angiogenesis in infarcted myocardium. Biomaterials. (2011) 32:2407-16. doi: 10.1016/j.biomaterials.2010.11.075

117. Freedman SB, Isner JM. Therapeutic angiogenesis for ischemic cardiovascular disease. J Mol Cell Cardiol. (2001) 33:379-93. doi: 10.1006/jmcc.2000.1329

118. Luo Z, Diaco M, Murohara T, Ferrara N, Isner JM, Symes JF. Vascular endothelial growth factor attenuates myocardial 
ischemia-reperfusion injury. Ann Thorac Surg. (1997) 64:993-8. doi: 10.1016/S0003-4975(97)00715-7

119. Hagikura K, Fukuda N, Yokoyama SI, Yuxin L, Kusumi Y, Matsumoto $\mathrm{T}$, et al. Low invasive angiogenic therapy for myocardial infarction by retrograde transplantation of mononuclear cells expressing the VEGF gene. Int J Cardiol. (2010) 142:56-64. doi: 10.1016/j.ijcard.2008.12.108

120. Kim D, Ku SH, Kim H, Jeong JH, Lee M, Kwon IC, et al. Simultaneous regulation of apoptotic gene silencing and angiogenic gene expression for myocardial infarction therapy: Single-carrier delivery of SHP-1 siRNA and VEGF-expressing pDNA. J Control Release. (2016) 243:182-94. doi: 10.1016/j.jconrel.2016.10.017

121. Moon H, Joo MK, Mok H, Lee M, Hwang KC, Kim SW, et al. MSCbased VEGF gene therapy in rat myocardial infarction model using facial amphipathic bile acid-conjugated polyethyleneimine. Biomaterials. (2014) 35:1744-54. doi: 10.1016/j.biomaterials.2013.11.019

122. Henry TD, Rocha-Singh K, Isner JM, Kereiakes DJ, Giordano FJ, Simons $\mathrm{M}$, et al. Intracoronary administration of recombinant human vascular endothelial growth factor to patients with coronary artery disease. Am Heart J. (2001) 142:872-80. doi: 10.1067/mhj.2001.118471

123. Yang Y, Shi C, Hou X, Zhao Y, Chen B, Tan B, et al. Modified VEGF targets the ischemic myocardium and promotes functional recovery after myocardial infarction. J Control Release. (2015) 213:27-35. doi: 10.1016/j.jconrel.2015.06.036

124. Henry TD, Annex BH, McKendall GR, Azrin MA, Lopez JJ, Giordano FJ, et al. The VIVA trial: vascular endothelial growth factor in ischemia for vascular angiogenesis. Circulation. (2003) 107:1359-65. doi: 10.1161/01.CIR.0000061911.47710.8A

125. Hendel Robert C, Henry Timothy D, Rocha-Singh K, Isner Jeffrey M, Kereiakes Dean J, Giordano Frank J, et al. Effect of intracoronary recombinant human vascular endothelial growth factor on myocardial perfusion. Circulation. (2000) 101:118-21. doi: 10.1161/01.CIR.101.2.118

126. Schumacher B, Pecher P, von Specht BU, Stegmann T. Induction of neoangiogenesis in ischemic myocardium by human growth factors. Circulation. (1998) 97:645-50. doi: 10.1161/01.CIR.97.7.645

127. Chen SL, Fu RH, Liao SF, Liu SP, Lin SZ, Wang YC. A PEG-based hydrogel for effective wound care management. Cell Transplant. (2018) 27:275-84. doi: $10.1177 / 0963689717749032$

128. Cruz-Acuña R, Quirós M, Huang S, Siuda D, Spence JR, Nusrat A, et al. PEG4MAL hydrogels for human organoid generation, culture, in vivo delivery. Nat Protoc. (2018) 13:2102-19. doi: 10.1038/s41596-018-0036-3

129. Hesse E, Freudenberg U, Niemietz T, Greth C, Weisser M, Hagmann S, et al. Peptide-functionalized starPEG/heparin hydrogels direct mitogenicity, cell morphology and cartilage matrix distribution in vitro and in vivo. J Tissue Eng Regenerat Med. (2018) 12:229-39. doi: 10.1002/term.2404

130. Shen YH, Shoichet MS, Radisic M. Vascular endothelial growth factor immobilized in collagen scaffold promotes penetration and proliferation of endothelial cells. Acta Biomaterial. (2008) 4:477-89. doi: 10.1016/j.actbio.2007.12.011

131. Steffens GC, Yao C, Prével P, Markowicz M, Schenck P, Noah EM, et al. Modulation of angiogenic potential of collagen matrices by covalent incorporation of heparin and loading with vascular endothelial growth factor. Tissue Eng. (2004) 10:1502-9. doi: 10.1089/ten.2004.10.1502

132. Yanagisawa-Miwa A, Uchida Y, Nakamura F, Tomaru T, Kido H, Kamijo T, et al. Salvage of infarcted myocardium by angiogenic action of basic fibroblast growth factor. Science. (1992) 257:1401. doi: $10.1126 /$ science. 1382313

133. Laham RJ, Chronos NA, Pike M, Leimbach ME, Udelson JE, Pearlman JD, et al. Intracoronary basic fibroblast growth factor (FGF-2) in patients with severe ischemic heart disease: results of a Phase I openlabel dose escalation study. J Am Coll Cardiol. (2000) 36:2132-9. doi: 10.1016/S0735-1097(00)00988-8

134. Ruel M, Laham RJ, Parker JA, Post MJ, Ware JA, Simons M, et al. Long-term effects of surgical angiogenic therapy with fibroblast growth factor 2 protein. J Thorac Cardiovasc Surg. (2002) 124:28-34. doi: 10.1067/mtc.2002.121974

135. Doi K, Ikeda T, Marui A, Kushibiki T, Arai Y, Hirose K, et al. Enhanced angiogenesis by gelatin hydrogels incorporating basic fibroblast growth factor in rabbit model of hind limb ischemia. Heart Vessels. (2007) 22:104-8. doi: 10.1007/s00380-006-0934-0
136. Zhao Y, Liu Z, Pan C, Li Z, Zhou J, Wang J, et al. Preparation of gelatin microspheres encapsulated with bFGF for therapeutic angiogenesis in a canine ischemic hind limb. J Biomater Sci Polym Ed. (2011) 22:665-82. doi: 10.1163/092050610X489880

137. Marui A, Tabata Y, Kojima S, Yamamoto M, Tambara K, Nishina T, et al. A novel approach to therapeutic angiogenesis for patients with critical limb ischemia by sustained release of basic fibroblast growth factor using biodegradable gelatin hydrogel an initial report of the Phase I-IIa Study. Circ J. (2007) 71:1181-6. doi: 10.1253/circj.71.1181

138. Kumagai M, Marui A, Tabata Y, Takeda T, Yamamoto M, Yonezawa A, et al. Safety and efficacy of sustained release of basic fibroblast growth factor using gelatin hydrogel in patients with critical limb ischemia. Heart Vessels. (2016) 31:713-21. doi: 10.1007/s00380-015-0677-x

139. Chu H, Chen CW, Huard J, Wang Y. The effect of a heparin-based coacervate of fibroblast growth factor-2 on scarring in the infarcted myocardium. Biomaterials. (2013) 34:1747-56. doi: 10.1016/j.biomaterials.2012.11.019

140. Pinto AR, Godwin JW, Rosenthal NA.Macrophages in cardiac homeostasis, injury responses and progenitor cell mobilisation. Stem Cell Res. (2014) 13:705-14. doi: 10.1016/j.scr.2014.06.004

141. Cheng W, Kajstura J, Nitahara JA, Li B, Reiss K, Liu Y, et al. Programmed myocyte cell death affects the viable myocardium after infarction in rats. Exp Cell Res. (1996) 226:316-27. doi: 10.1006/excr.1996.0232

142. Palojoki E, Saraste A, Eriksson A, Pulkki K, Kallajoki M, Voipio-Pulkki LM, et al. Cardiomyocyte apoptosis and ventricular remodeling after myocardial infarction in rats. Am J Physiol Heart Circ Physiol. (2001) 280:H2726-31. doi: 10.1152/ajpheart.2001.280.6.H2726

143. Sluijter JPG, Condorelli G, Davidson SM, Engel FB, Ferdinandy P, Hausenloy DJ, et al. Novel therapeutic strategies for cardioprotection. Pharmacol Therap. (2014) 144:60-70. doi: 10.1016/j.pharmthera.2014.05.005

144. Harada M, Qin Y, Takano H, Minamino T, Zou Y, Toko H, et al. G-CSF prevents cardiac remodeling after myocardial infarction by activating the Jak-Stat pathway in cardiomyocytes. Nat Med. (2005) 11:305. doi: $10.1038 / \mathrm{nm} 1199$

145. Moon C, Krawczyk M, Ahn D, Ahmet I, Paik D, Lakatta EG, et al. Erythropoietin reduces myocardial infarction and left ventricular functional decline after coronary artery ligation in rats. Proc Natl Acad Sci USA. (2003) 100:11612. doi: 10.1073/pnas.1930406100

146. Fiordaliso F, Chimenti S, Staszewsky L, Bai A, Carlo E, Cuccovillo I, et al. A nonerythropoietic derivative of erythropoietin protects the myocardium from ischemia-reperfusion injury. Proc Natl Acad Sci USA. (2005) 102:2046. doi: 10.1073/pnas.0409329102

147. Troncoso R, Ibarra C, Vicencio JM, Jaimovich E, Lavandero S. New insights into IGF-1 signaling in the heart. Trends Endocrinol Metab. (2014) 25:12837. doi: 10.1016/j.tem.2013.12.002

148. Buerke M, Murohara T, Skurk C, Nuss C, Tomaselli K, Lefer AM. Cardioprotective effect of insulin-like growth factor I in myocardial ischemia followed by reperfusion. Proc Natl Acad Sci USA. (1995) 92:8031. doi: $10.1073 /$ pnas. 92.17 .8031

149. Gallego-Colon E, Sampson RD, Sattler S, Schneider MD, Rosenthal N, Tonkin J. Cardiac-Restricted IGF-1Ea overexpression reduces the early accumulation of inflammatory myeloid cells and mediates expression of extracellular matrix remodelling genes after myocardial infarction. Mediat Inflamm. (2015) 2015:484357. doi: 10.1155/2015/484357

150. Li Q, Li B, Wang X, Leri A, Jana KP, Liu Y, et al. Overexpression of insulinlike growth factor- 1 in mice protects from myocyte death after infarction, attenuating ventricular dilation, wall stress, and cardiac hypertrophy. J Clin Investig. (1997) 100:1991-9. doi: 10.1172/JCI119730

151. Gallego-Colon E, Villalba M, Tonkin J, Cruz F, Bernal JA, JimenezBorregureo LJ, et al. Intravenous delivery of adeno-associated virus 9-encoded IGF-1Ea propeptide improves post-infarct cardiac remodelling. NPJ Regen Med. (2016) 1:16001. doi: 10.1038/npjregenmed.2016.1

152. Duerr RL, Huang S, Miraliakbar HR, Clark R, Chien KR, Ross J Jr. Insulinlike growth factor-1 enhances ventricular hypertrophy and function during the onset of experimental cardiac failure. J Clin Investig. (1995) 95:619-27. doi: $10.1172 / J C I 117706$

153. Chao W, Matsui T, Novikov MS, Tao J, Li L, Liu H, et al. Strategic advantages of insulin-like growth factor-I expression for cardioprotection. J Gene Med. (2002) 5:277-86. doi: 10.1002/jgm.347 
154. Santini MP, Tsao L, Monassier L, Theodoropoulos C, Carter J, Lara-Pezzi E, et al. Enhancing repair of the mammalian heart. Circ Res. (2007) 100:173240. doi: 10.1161/CIRCRESAHA.107.148791

155. Bilbao D, Luciani L, Johannesson B, Piszczek A, Rosenthal N. Insulin-like growth factor-1 stimulates regulatory $\mathrm{T}$ cells and suppresses autoimmune disease. EMBO Mol Med. (2014) 6:1423-35. doi: 10.15252/emmm.201303376

156. Johannesson B, Sattler S, Semenova E, Pastore S, Kennedy-Lydon TM, Sampson RD, et al. Insulin-like growth factor-1 induces regulatory $\mathrm{T}$ cellmediated suppression of allergic contact dermatitis in mice. Dis Models Mech. (2014) 7:977-85. doi: 10.1242/dmm.015362

157. Wang X, Li Q, Hu Q, Suntharalingam P, From AHL, Zhang J. Intramyocardial injection of both growth factors and heart derived Sca1+/CD31- cells attenuates post-MI LV remodeling more than does cell transplantation alone: neither intervention enhances functionally significant cardiomyocyte regeneration. PLOS ONE. (2014) 9:e95247. doi: 10.1371/journal.pone.0095247

158. Zhang M, Ai WW, Mei ZL, Hu YH, Zhang ZL. Delivery of biotinylated IGF1 with biotinylated self-assembling peptides combined with bone marrow stem cell transplantation promotes cell therapy for myocardial infarction. Exp Therap Med. (2017) 14:3441-6. doi: 10.3892/etm.2017.4982

159. Liebesny PH, Byun S, Hung HH, Pancoast JR, Mroszczyk KA, Young WT, et al. Growth factor-mediated migration of bone marrow progenitor cells for accelerated scaffold recruitment. Tissue Eng Part A. (2016) 22:917-27. doi: 10.1089/ten.tea.2015.0524

160. Wang X, Zhang J, Cui W, Fang Y, Li L, Ji S, et al. Composite Hydrogel Modified by IGF-1C domain improves stem cell therapy for limb ischemia. ACS Appl Mater Interfaces. (2018) 10:4481-93. doi: 10.1021/acsami.7b17533

161. Feng G, Zhang J, Li Y, Nie Y, Zhu D, Wang R, et al. IGF-1 C Domainmodified hydrogel enhances cell therapy for AKI. J Am Soc Nephrol. (2016) 27:2357-69. doi: 10.1681/ASN.2015050578

162. Wang F, Li Z, Khan M, Tamama K, Kuppusamy P, Wagner WR, et al. Injectable, rapid gelling and highly flexible hydrogel composites as growth factor and cell carriers. Acta Biomater. (2010) 6:1978-91. doi: 10.1016/j.actbio.2009.12.011

163. Pentassuglia L, Sawyer DB. The role of Neuregulin-1beta/ErbB signaling in the heart. Exp Cell Res. (2009) 315:627-37. doi: 10.1016/j.yexcr.2008.08.015

164. Kirabo A, Ryzhov S, Gupte M, Sengsayadeth S, Gumina RJ, Sawyer DB, et al. Neuregulin- $1 \beta$ induces proliferation, survival and paracrine signaling in normal human cardiac ventricular fibroblasts. J Mol Cell Cardiol. (2017) 105:59-69. doi: 10.1016/j.yjmcc.2017.03.001

165. Hill MF, Patel AV, Murphy A, Smith HM, Galindo CL, Pentassuglia L, et al. Intravenous glial growth factor 2 (GGF2) isoform of neuregulin- $1 \beta$ improves left ventricular function, gene and protein expression in rats after myocardial infarction. PLoS ONE. (2013) 8:e55741. doi: 10.1371/journal.pone.0055741

166. Galindo CL, Kasasbeh E, Murphy A, Ryzhov S, Lenihan S, Ahmad FA, et al. Anti-remodeling and anti-fibrotic effects of the neuregulin-1 $\beta$ glial growth factor 2 in a large animal model of heart failure. J Am Heart Assoc. (2014) 3:e000773. doi: 10.1161/JAHA.113.000773

167. Parry TJ, Ganguly A, Troy EL, Luis Guerrero J, Iaci JF, Srinivas M, et al. Effects of neuregulin GGF2 (cimaglermin alfa) dose and treatment frequency on left ventricular function in rats following myocardial infarction. Eur J Pharmacol. (2017) 796:76-89. doi: 10.1016/j.ejphar.2016.12.024

168. Lenihan DJ, Anderson SA, Lenneman CG, Brittain E, Muldowney AS III, Mendes L, et al. Single Ascending Dose Study of Cimaglermin Alfa

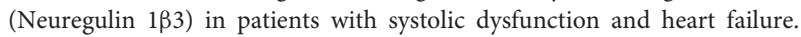
JACC Basic Transl Sci. (2016) 1:576-86. doi: 10.1016/j.jacbts.2016.09.005

169. Cohen JE, Purcell BP, MacArthur JW, Mu A, Shudo Y, Patel JB, et al. A bioengineered hydrogel system enables targeted and sustained intramyocardial delivery of neuregulin, activating the cardiomyocyte cell cycle and enhancing ventricular function in a murine model of ischemic cardiomyopathy. Circ Heart Fail. (2014) 7:619-26. doi: 10.1161/CIRCHEARTFAILURE.113.001273

170. Pascual-Gil S, Simón-Yarza T, Garbayo E, Prósper F, Blanco-Prieto MJ. Cytokine-loaded PLGA and PEG-PLGA microparticles showed similar heart regeneration in a rat myocardial infarction model. Int J Pharm. (2017) 523:531-3. doi: 10.1016/j.ijpharm.2016.11.022

171. Garbayo E, Gavira JJ, de Yebenes MG, Pelacho B, Abizanda G, Lana H, et al. Catheter-based Intramyocardial Injection of FGF1 or NRG1-loaded MPs improves cardiac function in a preclinical model of ischemia-reperfusion. Sci Rep. (2016) 6:25932. doi: 10.1038/srep25932

172. Panahi M, Vadgama N, Kuganesan M, Ng FS, Sattler S. Immunopharmacology of post-myocardial infarction and heart failure medications. J Clin Med. (2018) 7:403. doi: 10.3390/jcm7110403

173. Liu Z, Wang H, Wang Y, Lin Q, Yao A, Cao F, et al. The influence of chitosan hydrogel on stem cell engraftment, survival and homing in the ischemic myocardial microenvironment. Biomaterials. (2012) 33:3093-106. doi: 10.1016/j.biomaterials.2011.12.044

174. Vecchies F, Sacco P, Decleva E, Menegazzi R, Porrelli D, Donati I, et al. Complex coacervates between a lactose-modified chitosan and hyaluronic acid as radical-scavenging drug carriers. Biomacromolecules. (2018) 19:393644. doi: 10.1021/acs.biomac.8b00863

175. Nakamura K, Yokohama S, Yoneda M, Okamoto S, Tamaki Y, Ito T, et al. High, but not low, molecular weight hyaluronan prevents T-cell-mediated liver injury by reducing proinflammatory cytokines in mice. J Gastroenterol. (2004) 39:346-54. doi: 10.1007/s00535-003-1301-x

176. Hemmati-Sadeghi S, Dey P, Ringe J, Haag R, Sittinger M, Dehne T. Biomimetic sulfated polyethylene glycol hydrogel inhibits proteoglycan loss and tumor necrosis factor- $\alpha$-induced expression pattern in an osteoarthritis in vitro model. J Biomed Mater Res Part B Appl Biomater. (2018) 107:490-500. doi: 10.1002/jbm.b.34139

177. Moore KW, de Waal Malefyt R, Coffman RL, O'Garra A. Interleukin-10 and the Interleukin-10 receptor. Ann Rev Immunol. (2001) 19:683-765. doi: 10.1146/annurev.immunol.19.1.683

178. Stumpf C, Seybold K, Petzi S, Wasmeier G, Raaz D, Yilmaz A, et al. Interleukin-10 improves left ventricular function in rats with heart failure subsequent to myocardial infarction. Eur J Heart Fail. (2014) 10:733-9. doi: 10.1016/j.ejheart.2008.06.007

179. Huhn RD, Radwanski E, Gallo J, Affrime MB, Sabo R, Gonyo G, et al. Pharmacodynamics of subcutaneous recombinant human interleukin10 in healthy volunteers. Clin Pharmacol Therap. (1997) 62:171-80. doi: 10.1016/S0009-9236(97)90065-5

180. Chen CW, Lee BG, Park DW, Kim K, Chu H, Kim K,et al. Controlled dual delivery of fibroblast growth factor- 2 and Interleukin-10 by heparin-based coacervate synergistically enhances ischemic heart repair. Biomaterials. (2015) 72:138-51. doi: 10.1016/j.biomaterials.2015.08.050

181. Koch M, Savvatis K, Scheeler M, Dhayat S, Bonaventura K, Pohl T, et al. Immunosuppression with an interleukin-2 fusion protein leads to improved LV function in experimental ischemic cardiomyopathy. Int Immunopharmacol. (2010) 10:207-12. doi: 10.1016/j.intimp.2009.11.001

182. An W, Yu Y, Zhang Y, Zhang Z, Yu Y, Zhao X. Exogenous IL19 attenuates acute ischemic injury and improves survival in male mice with myocardial infarction. Br J Pharmacol. (2019) 176:699-710. doi: 10.1111/bph.14549

183. Gao C, Liu Y, Yu Q, Yang Q, Li B, Sun L, et al. TNF- $\alpha$ antagonism ameliorates myocardial ischemia-reperfusion injury in mice by upregulating adiponectin. Am J Physiol Heart Circ Physiol. (2015) 308:H1583-91. doi: 10.1152/ajpheart.00346.2014

184. Friedrich EE, Sun LT, Natesan S, Zamora DO, Christy RJ, Washburn NR. Effects of hyaluronic acid conjugation on anti-TNF- $\alpha$ inhibition of inflammation in burns. J Biomed Mater Res Part A. (2014) 102:1527-36. doi: 10.1002/jbm.a.34829

185. Sun LT, Bencherif SA, Gilbert TW, Farkas AM, Lotze MT, Washburn NR. Biological activities of cytokine-neutralizing hyaluronic acidantibody conjugates. Wound Repair Regen. (2010) 18:302-10. doi: 10.1111/j.1524-475X.2010.00591.X

186. Janjic J, Berlec A, Bagia C, Liu L, Jeric I, Gach M, et al. NIR and MR imaging supported hydrogel based delivery system for anti-TNF alpha probiotic therapy of IBD. In: SPIE BiOS. San Francisco, CA (2016).

187. Spinale FG. Myocardial matrix remodeling and the matrix metalloproteinases: influence on cardiac form and function. Physiol Rev. (2007) 87:1285-342. doi: 10.1152/physrev.00012.2007

188. Dormán G, Cseh S, Hajdú I, Barna L, Kónya D, Kupai K, et al. Matrix metalloproteinase inhibitors. Drugs. (2010) 70:949-64. doi: 10.2165/11318390-000000000-00000.

189. Eckhouse SR, Purcell BP, McGarvey JR, Lobb D, Logdon CB, Doviak H, et al. Local hydrogel release of recombinant TIMP-3 attenuates adverse left 
ventricular remodeling after experimental myocardial infarction. Sci Transl Med. (2014) 6:223ra21. doi: 10.1126/scitranslmed.3007244

190. Barlow SC, Doviak H, Jacobs J, Freeburg LA, Perreault PE, Zellars KN, et al. Intracoronary delivery of recombinant TIMP-3 after myocardial infarction: effects on myocardial remodeling and function. Am J Physiol Heart Circ Physiol. (2017) 313:H690-9. doi: 10.1152/ajpheart.00114.2017

191. Turner N, Porter K. Function and fate of myofibroblasts after myocardial infarction. Fibrogenesis Tissue Repair. (2013). 6:5. doi: 10.1186/1755-1536-6-5

192. Koblizek TI, Weiss C, Yancopoulos GD, Deutsch U, Risau W. Angiopoietin1 induces sprouting angiogenesis in vitro. Curr Biol. (1998) 8:529-32. doi: 10.1016/S0960-9822(98)70205-2

193. Suri C, McClain J, Thurston G, McDonald DM, Zhou H, Oldmixon EH, et al. Increased vascularization in mice overexpressing angiopoietin-1. Science. (1998) 282:468. doi: 10.1126/science.282.5388.468

194. Lee J, Kim KE, Choi DK, Jang JY, Jung JJ, Kiyonari H, et al. Angiopoietin1 guides directional angiogenesis through integrin $\alpha \mathrm{v} \beta 5$ signaling for recovery of ischemic retinopathy. Sci Transl Med. (2013) 5:203ra127. doi: $10.1126 /$ scitranslmed.3006666

195. Rufaihah AJ, Johari NA, Vaibavi SR, Plotkin M, Di Thien DT, Kofidis T, et al. Dual delivery of VEGF and ANG-1 in ischemic hearts using an injectable hydrogel. Acta Biomater. (2017) 48:58-67. doi: 10.1016/j.actbio.2016.10.013

196. Phelps EA, Enemchukwu NO, Fiore VF, Sy JC, Murthy N, Sulchek TA, et al. Maleimide cross-linked bioactive PEG hydrogel exhibits improved reaction kinetics and cross-linking for cell encapsulation and in situ delivery. $A d v$ Mater. (2011) 24:64-70. doi: 10.1002/adma.201103574

197. Salimath AS, Phelps EA, Boopathy AV, Brown M, García AJ, Davis ME. Dual delivery of hepatocyte and vascular endothelial growth factors via a proteasedegradable hydrogel improves cardiac function in rats. PLoS ONE. (2012) 7:e50980. doi: 10.1371/journal.pone.0050980

198. Hao X, Silva EA, Månsson-Broberg A, Grinnemo H, Siddiqui AJ, Dellgren G, et al. Angiogenic effects of sequential release of VEGF-A165 and PDGF-BB with alginate hydrogels after myocardial infarction. Cardiovasc Res. (2007) 75:178-85. doi: 10.1016/j.cardiores.2007.03.028

199. Hoch RV, Soriano P. Roles of PDGF in animal development. Development. (2003) 130:4769-84. doi: 10.1242/dev.00721

200. Vantler M, Karikkineth BC, Naito H, Tiburcy M, Didié M, Nose M, et al. PDGF-BB protects cardiomyocytes from apoptosis and improves contractile function of engineered heart tissue. J Mol Cell Cardiol. (2010) 48:1316-23. doi: 10.1016/j.yjmcc.2010.03.008

201. Hsieh PC, Davis ME, Gannon J, MacGillivray C, Lee RT. Controlled delivery of PDGF-BB for myocardial protection using injectable self-assembling peptide nanofibers. J Clin Investig. (2006) 116:237-48. doi: 10.1172/JCI25878

202. Ruvinov E, Leor J, Cohen S. The promotion of myocardial repair by the sequential delivery of IGF-1 and HGF from an injectable alginate biomaterial in a model of acute myocardial infarction. Biomaterials. (2011) 32:565-78. doi: 10.1016/j.biomaterials.2010.08.097

203. Cittadini A, Monti MG, Petrillo V, Esposito G, Imparato G, Luciani A, et al. Complementary therapeutic effects of dual delivery of insulinlike growth factor-1 and vascular endothelial growth factor by gelatin microspheres in experimental heart failure. Eur J Heart Fail. (2014) 13:126474. doi: 10.1093/eurjhf/hfr143

204. Ma Z, Nelson DM, Hong Y, Wagner WR. Thermally responsive injectable hydrogel incorporating methacrylate-polylactide for hydrolytic lability. Biomacromolecules. (2010) 11:1873-81. doi: 10.1021/bm1004299

205. Suleiman MS, Singh RJ, Stewart CE. Apoptosis and the cardiac action of insulin-like growth factor I. Pharmacol Therap. (2007) 114:278-94. doi: 10.1016/j.pharmthera.2007.03.001

206. Tous E, Ifkovits JL, Koomalsingh KJ, Shuto T, Soeda T, Kondo N, et al. Influence of injectable hyaluronic acid hydrogel degradation behavior on infarction-induced ventricular remodeling. Biomacromolecules. (2011) 12:4127-135. doi: 10.1021/bm201198x

207. Guo L, Akahori H, Harari E, Smith SL, Polavarapu R, Karmali V, et al. $\mathrm{CD} 163+$ macrophages promote angiogenesis and vascular permeability accompanied by inflammation in atherosclerosis. J Clin Investig. (2018) 128:1106-24. doi: 10.1172/JCI93025
208. Koudstaal S, Bastings MM, Feyen DA, Waring CD, van Slochteren FJ, Dankers PY, et al. Sustained delivery of insulin-like growth factor-1/hepatocyte growth factor stimulates endogenous cardiac repair in the chronic infarcted pig heart. J Cardiovasc Translat Res. (2014) 7:232-41. doi: 10.1007/s12265-0139518-4

209. Zhang D, Fan GC, Zhou X, Zhao T, Pasha Z, Xu M, et al. Overexpression of CXCR4 on mesenchymal stem cells augments myoangiogenesis in the infarcted myocardium. J Mol Cell Cardiol. (2008) 44:281-92. doi: $10.1016 /$ j.yjmcc.2007.11.010

210. Theiss HD, Vallaster M, Rischpler C, Krieg L, Zaruba MM, Brunner S, et al. Dual stem cell therapy after myocardial infarction acts specifically by enhanced homing via the SDF-1/CXCR4 axis. Stem Cell Res. (2011) 7:244-55. doi: 10.1016/j.scr.2011.05.003

211. Awada HK, Long DW, Wang Z, Hwang MP, Kim K, Wang Y. A single injection of protein-loaded coacervategel significantly improves cardiac function post infarction. Biomaterials. (2017) 125:65-80. doi: 10.1016/j.biomaterials.2017. 02.020

212. Waters R, Alam P, Pacelli S, Chakravarti AR, Ahmed PH, Paul A. Stem cellinspired secretome-rich injectable hydrogel to repair injured cardiac tissue. Acta Biomater. (2018) 69:95-106. doi: 10.1016/j.actbio.2017.12.025

213. Wang LL, Burdick JA. Engineered hydrogels for local and sustained delivery of RNA-interference therapies. Adv Healthcare Mater. (2017) 6:1601041. doi: 10.1002/adhm.201601041

214. Wang LL, Chung JJ, Li EC, Uman S, Atluri P, Burdick JA. Injectable and protease-degradable hydrogel for siRNA sequestration and triggered delivery to the heart. J Control Release. (2018) 285:152-61. doi: 10.1016/j.jconrel.2018.07.004

215. Paul A, Hasan A, Kindi HA, Gaharwar AK, Rao VTS, Nikkhah M, et al. Injectable graphene oxide/hydrogel-based angiogenic gene delivery system for vasculogenesis and cardiac repair. ACS Nano. (2014) 8:8050-62. doi: 10.1021/nn5020787

216. Sultana N, Magadum A, Hadas Y, Kondrat J, Singh N, Youssef E, et al. Optimizing cardiac delivery of modified mRNA. Mol Ther J Am Soc Gene Ther. (2017) 25:1306-15. doi: 10.1016/j.ymthe.2017. 03.016

217. McManus DD, Shah SJ, Fabi MR, Rosen A, Whooley MA, Schiller NB. Prognostic value of left ventricular end-systolic volume index as a predictor of heart failure hospitalization in stable coronary artery disease: data from the Heart and Soul Study. J Am Soc Echocardiogr. (2009) 22:190-7. doi: 10.1016/j.echo.2008.11.005

218. Mann DL, Lee RJ, Coats AJS, Neagoe G, Dragomir D, Pusineri E, et al. One-year follow-up results from AUGMENT-HF: a multicentre randomized controlled clinical trial of the efficacy of left ventricular augmentation with Algisyl in the treatment of heart failure. Eur J Heart Fail. (2015) 18:314-25. doi: 10.1002/ejhf.449

219. Suarez SL, Rane AA, Muñoz A, Wright AT, Zhang SX, Braden $\mathrm{RL}$, et al. Intramyocardial injection of hydrogel with high interstitial spread does not impact action potential propagation. Acta Biomater. (2015) 26:13-22. doi: 10.1016/j.actbio.2015. 08.004

220. Menasché P. Cell therapy trials for heart regeneration - lessons learned and future directions. Nat Rev Cardiol. (2018). 15:659-71. doi: 10.1038/s41569-018-0013-0

Conflict of Interest Statement: The authors declare that the research was conducted in the absence of any commercial or financial relationships that could be construed as a potential conflict of interest.

Copyright $\odot 2019$ Ferrini, Stevens, Sattler and Rosenthal. This is an open-access article distributed under the terms of the Creative Commons Attribution License (CC $B Y)$. The use, distribution or reproduction in other forums is permitted, provided the original author(s) and the copyright owner(s) are credited and that the original publication in this journal is cited, in accordance with accepted academic practice. No use, distribution or reproduction is permitted which does not comply with these terms. 